INEEL/EXT-99-01029

September 1999

\title{
SCDAP/RELAP5 LOWER CORE PLATE MODEL
}

\author{
E. W. Coryell \\ F. P. Griffin
}

L OCKHEED MARTIN 


\section{NOTICE}

This information was prepared as an account of work sponsored by an agency of the U.S. Government. Neither the U.S. Government nor any agency thereof, nor any of their employees, makes any warranty, express or implied, or assumes any legal liability or responsibility for any third party's use, or the results of such use, of any information, apparatus, product, or process disclosed herein, or represents that its use by such third party would not infringe privately owned rights. The views expressed herein are not necessarily those of the U.S. Nuclear Regulatory Commission. 
INEEL/EXT-99-01029

\title{
SCDAP/RELAP5 LOWER CORE PLATE MODEL
}

\author{
E.W. Coryell (INEEL) \\ F.P. Griffin (ORNL)
}

Published September 1999

Idaho National Engineering and Environmental Laboratory

Lockheed Martin Idaho Technologies

Idaho Falls, Idaho 83415

Prepared for

Division of Systems Technology

Office of Nuclear Regulatory Research

U.S. Nuc lear Regulatory Commission

Washington, DC 20555-0001

NRC Job Code W6095 



\begin{abstract}
The SCDAP/RELAP5 computer code is a best-estimate analysis tool for performing nuclear reactor severe accident simulations. This report describes the justification, theory, implementation, and testing of a new modeling capability which will refine the analysis of the movement of molten material from the core region to the vessel lower head. As molten material moves from the core region through the core support structures it may encounter conditions which will cause it to freeze in the region of the lower core plate, delaying it's arrival to the vessel head. The timing of this arrival is significant to reactor safety, because during the time span for material relocation to the lower head, the core may be experiencing steam-limited oxidation. The time at which hot material arrives in a coolant-filled lower vessel head, thereby significantly increasing the steam flow rate through the core region, becomes significant to the progression and timing of a severe accident.
\end{abstract}

This report is a revision of a report INEEL/EXT-00707, entitled "Preliminary Design Report for SCDAP/RELAP5 Lower Core Plate Model". 


\section{Summary}

The SCDAP/RELAP5 computer code is a best-estimate analysis tool for performing nuclear reactor severe accident simulations. Under primary sponsorship of the U.S. Nuclear Regulatory Commission (NRC), Idaho National Engineering and Environmental Laboratory (INEEL) is responsible for overall maintenance of this code and for improvements which will refine and improve the ability of the code to provide a best-estimate analysis of reactor behavior. SCDAP/RELAP5 severe accident models are currently available to represent the active core region, the upper plenum structures, and debris which falls from the core region into the bottom head of the vessel. However, no model has been available to examine the effect of the core supporting structures on the flow of material between the core and the lower head.

This report describes the justification, theory, implementation, and testing of a new modeling capability which will refine the analysis of the movement of molten material from the core region to the vessel lower head. As molten material moves from the core region through the core support structures it may encounter conditions which will cause it to freeze in the region of the lower core plate, delaying it's arrival to the vessel head. The timing of this arrival is significant to reactor safety, because during the time span for material relocation, the core may be experiencing steam-limited oxidation. The time at which hot material arrives in a coolant-filled lower vessel head, thereby significantly increasing the steam flow rate through the core region, becomes significant to the progression and timing of a severe accident. 


\section{Contents}

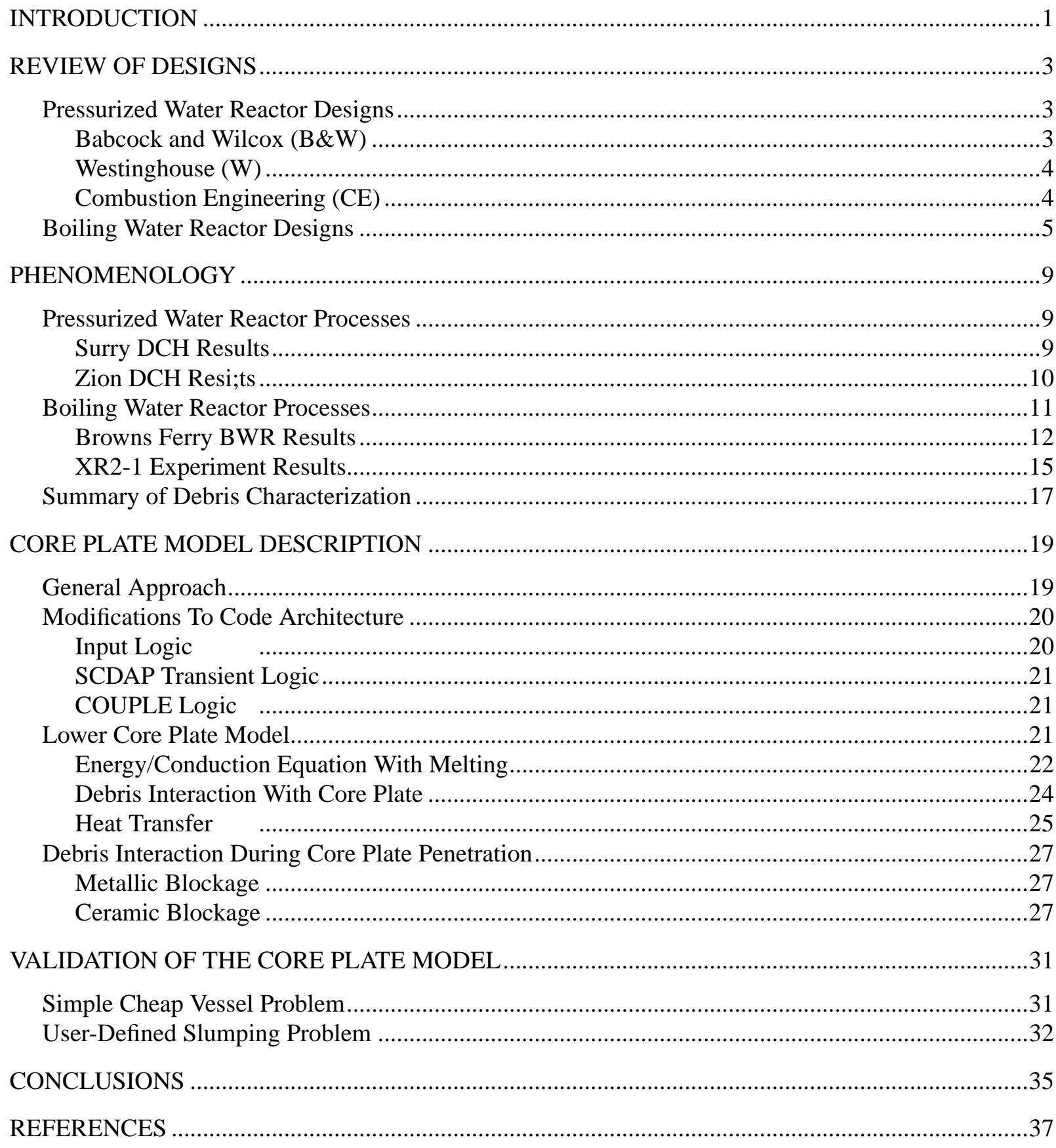





\section{List of Figures}

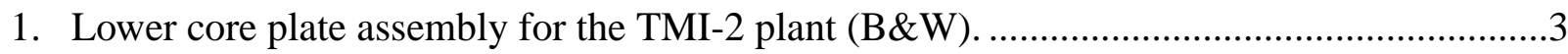

2. Zion lower core plate assembly (Westinghouse). .......................................................4

3. Waterford lower core plate assembly (Combustion Engineering). ....................................5

4. Position of core plate relative to other structures in BWR vessel....................................6

5. Top and side views of BWR core plate assembly. ..................................................

6. Detailed views of other structures located in BWR core plate region.................................8

7. Predicted lower plenum debris height for Browns Ferry STSB accident. .........................14

8. Cross-sectional view of XR2-1 test assembly .............................................................15

9. Drainage paths for molten metallic material during the XR2-1 experiment. ......................17

10. Architecture of material relocation subroutines............................................................22

11. Nomenclature for solution of 1-D heat conduction equation at each axial level...............23

12. Representation of molten pool failure and material relocating to core plate.....................25

13. Blockage of core plate penetrations by metallic material.............................................28

14. Blockage of core plate penetration by ceramic material.................................................29

15. Nodalization of Simple Cheap Vessel Problem ...........................................................31

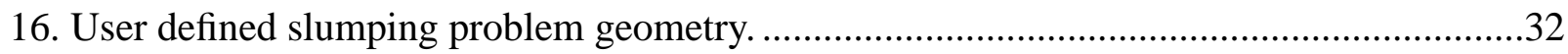

\section{List of Tables}

1. Approximate dimensions for components in lower core support assemblies.................5

2. Debris parameters during Surry DCH study. ......................................................10

3. Debris parameters during Zion DCH study. ....................................................... 11

4. Predicted event times for Browns Ferry STSB accident..........................................13

5. Range for variables used to estimate pool heat transfer parameters, .........................23 


\section{INTRODUCTION}

The SCDAP/RELAP5 computer code ${ }^{1}$ is a best-estimate analysis tool for performing nuclear reactor severe accident simulations. Under primary sponsorship of the U.S. Nuclear Regulatory Commission (NRC), Idaho National Engineering and Environmental Laboratory (INEEL) is responsible for overall maintenance of this code and for improvements for pressurized water reactor (PWR) applications. Since 1991, Oak Ridge National Laboratory (ORNL) has been improving SCDAP/RELAP5 for boiling water reactor (BWR) applications. The RELAP5 portion of the code performs the thermal-hydraulic calculations for both normal and severe accident conditions. The structures within the reactor vessel and coolant system can be represented with either RELAP5 heat structures or SCDAP/RELAP5 severe accident structures. The RELAP5 heat structures are limited to normal operating conditions (i.e., no structural oxidation, melting, or relocation), while the SCDAP portion of the code is capable of representing structural degradation and core damage progression that can occur under severe accident conditions.

SCDAP/RELAP5 severe accident models are currently available to represent (1) the intact structures with associated debris located in the active core region, (2) the intact structures located in the upper plenum above the core, and (3) debris which falls from the core region into the bottom head of the vessel. The SCDAP/RELAP5 core component models (examples are the fuel rod, PWR control rod, and BWR control blade/channel box components) are generally applied to describe structures in the active core region. SCDAP/RELAP5's lower plenum debris model (referred to as the COUPLE module) is generally applied in the hemispherical region of the bottom head. In the current version of SCDAP/RELAP5, the structures located between the bottom head and the bottom of active fuel can only be represented by RELAP5 heat structures (i.e., no SCDAP/RELAP5 severe accident models are available).

At the beginning of a severe accident transient, the reactor vessel coolant level falls until some or all of the core becomes uncovered and begins to heat up. Significant oxidation of the metallic surfaces begins after temperatures exceed about $1000 \mathrm{~K}$, and melting and eutectic liquefaction of the control rod/blade materials occur in the temperature range from about 1200 to $1730 \mathrm{~K}$. During the early phase of a severe accident, this molten metallic material relocates downward and freezes when it encounters a cooler environment. If water is still present in the lower portion of the active core, this solidification will occur within the core region, which is treated by existing SCDAP/RELAP5 mechanistic models. However, once the coolant inventory decreases sufficiently to allow the active core to become completely dry, the molten material relocates below the active core.

Experimental evidence, as well as several analyses, have indicated that amounts of molten metallic material on the order of several metric tons will relocate into and through the core plate region. The relocation of this molten metallic material is expected to occur over an extended period of time $(\sim 2,000 \mathrm{~s})$. The XR2-1 experiment, a BWR metallic melt relocation experiment conducted at Sandia National Laboratories, indicates that as much as $70 \%$ of the metallic relocating material will freeze within the core plate region, at least temporarily, to form non-coherent, localized blockages. During the later phases of the transient, analyses indicate that large amounts (potentially 10's of metric tons) of primarily molten ceramic material will relocate into and through the core plate region. There seems to be little doubt that relocation of material mass of this magnitude and at the temperatures expected, will cause the lower core plate to melt and/or fail if it is retained upon the structure. However, the relative timing of the relocation of this molten metallic and ceramic material is significant. During the time frame of the relocation the core region is 
relatively high in temperature, but is in a steam-starved or steam-limited environment. The relocation of the molten material into a pool of coolant which may exist low in the reactor vessel could significantly impact the predicted transient behavior by generating sufficient steam to change the core-region response.

This report describes the modifications made to SCDAP/RELAP5 which treat the thermal response of the structures in the core plate region as molten material relocates downward from the core, through the core plate region, and into the lower plenum. The original design was a joint task between INEEL and ORNL, with INEEL ${ }^{\mathrm{a}}$ focusing on PWR-specific design, and $\mathrm{ORNL}^{\mathrm{b}}$ focusing upon the BWR-specific aspects. The implementation and testing has been done entirely within the INEEL.

Chapter 2 describes the structures in the core plate region that must be represented by the proposed model. Chapter 3 presents the available information about the damage progression that is anticipated to occur in the core plate region during a severe accident, including typical SCDAP/RELAP5 simulation results. Chapter 4 provides a description of the implementation of the model and Chapter 5 discusses the testing done to verify the design and implementation of the model.

a. INEEL task specified by Task 11 of Standard Order for DOE Work (SOEW) "Job Code Title: $\underline{\text { SCDAP/ }}$ RELAP5 Code Development \& Assessment", Job Code Number W6095, December 23, 1997.

b. ORNL task specified by Task 6 of Job Code Number W6581 entitled "SCDAP/RELAP5 BWR Model Development for Severe Accidents". 


\section{REVIEW OF DESIGNS}

A review of currently operating plants was undertaken to categorize plant-specific features. The PWR review has been previously documented ${ }^{2}$, while the BWR review is original to this report.

\section{Pressurized Water Reactor Designs}

Representative PWR designs were categorized by vendor, with Final Safety Analysis Reports (FSAR) of the following plants providing design information, except where noted: Three Mile Island-2 $(\mathrm{TMI}-2)^{3}$ for Babcock and Wilcox, Waterford ${ }^{4}$ and Calvert Cliffs ${ }^{5}$ for Combustion Engineering, and Braidwood $^{6}$ and Zion Station ${ }^{7}$ for Westinghouse. The primary purpose of this review was to determine the general types of geometries and materials that must be addressed in the design of the SCDAP/RELAP5 model. It does not address plant specific features necessary to develop detailed input decks for the analysis of individual plants. For example, it is anticipated that the same geometric and phenomenological models would be applicable to the Zion and Surry plants, since both plants are Westinghouse designs. However, because of individual plant differences, such as core and downcomer flow bypass, the input models for these two plants will be noticeably different.

\section{Babcock and Wilcox (B\&W)}

The lower grid assembly, or lower core support assembly, in TMI-2 supports most of the reactor internal structure. All major components in the lower core support assembly are made of stainless steel. The lower grid assembly, shown in Figure 1, consists of two grid structures, separated by short tubular columns. The two grids are surrounded by a forged, flanged cylinder, with the top flange of the forged cylinder bolted to the lower flange of the core barrel. The upper plate in this assembly is a perforated plate, while the lower structure is a machined forging. The columns transfer loads to the bottom grid, which carries the loads in bending, The core barrel then transmits the load in tension to the reactor vessel. A perforated flat plate located midway between the grid structures aids in distributing coolant flow. Approximate dimensions for components of the lower grid assembly are given in Table 1.

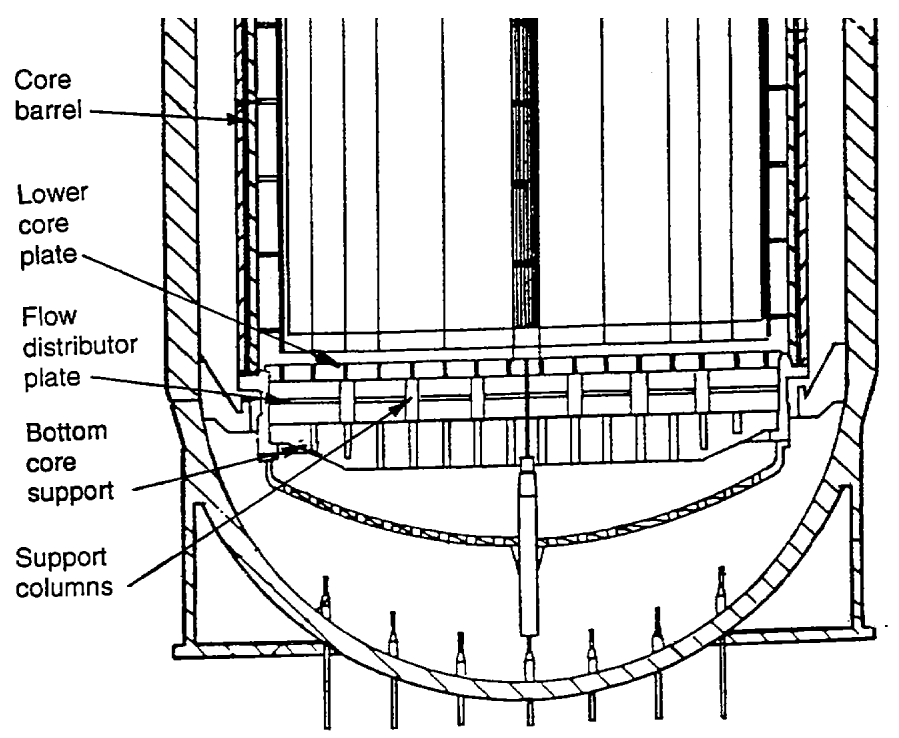

Figure 1. Lower core plate assembly for the TMI-2 plant (B\&W). 


\section{Westinghouse (W)}

The major support for reactor internal structures in the Westinghouse plants is the lower core support assembly, shown in Figure 2. Components which provide support in this assembly include two plates (the lower core plate and bottom core support) which are separated by support columns and surrounded by the core barrel. The support columns provide stiffness and transmit the core load to the core support, which carries the load in bending. The bottom core support, which is the lowest plate in this assembly, is welded to the core barrel, which hangs from a ledge in the reactor head flange. So again, the core barrel carries the dead load of reactor internal structures in tension. Approximate dimensions for components of the lower core support assembly are given in Table 1 .

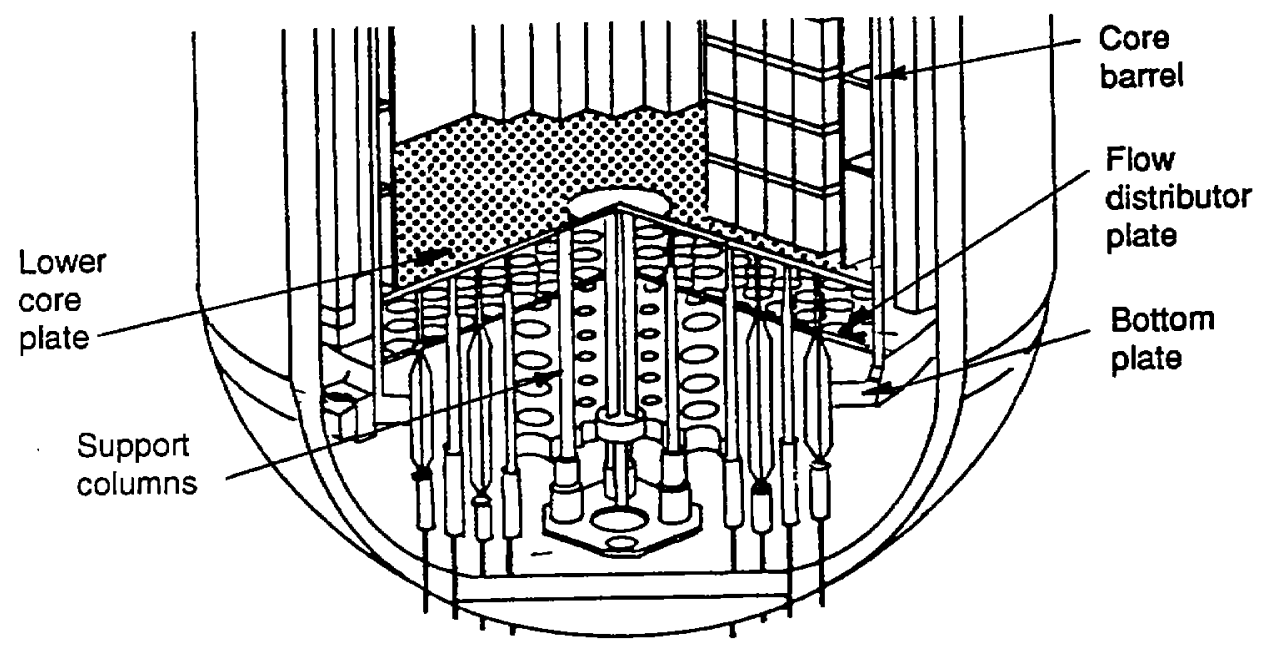

Figure 2. Zion lower core plate assembly (Westinghouse).

Note that in the Westinghouse RESAR design, the core rests directly on the bottom plate (similar to the bottom core support), which hangs from the end of the core barrel. The bottom plate is $44.5 \mathrm{~cm}$. thick in this design.

\section{Combustion Engineering (CE)}

Figure 3 shows the lower support assembly which supports reactor internal structures in the Waterford plant. The lower support assembly consists of a lower core plate (directly under the fuel assemblies), support columns, support beams, bottom core support, and surrounding cylinder, all made of Type 304 stainless steel. Loads to the lower core plate are transmitted through the support columns to the support beams. The support beams transform support column (point) loads to line loads on the bottom core support. The bottom core support carries the line loads in bending, transmitting the load to the core barrel, which carries it in tension. Approximate dimensions for components of the lower core support assembly 
are given in Table 1.

Table 1. Approximate dimensions for components in lower core support assemblies.

\begin{tabular}{|c|c|c|c|c|}
\hline \multicolumn{2}{|c|}{ Generic Name } & B\&W & W & CE \\
\hline \hline \multirow{2}{*}{$\begin{array}{c}\text { Lower Core } \\
\text { Plate }\end{array}$} & Diameter $(\mathrm{cm})$ & 356 & 373 & 363 \\
\cline { 2 - 5 } & Thickness $(\mathrm{cm})$ & 18.4 & 5.1 & 5.1 \\
\hline \multirow{2}{*}{$\begin{array}{c}\text { Bottom Core } \\
\text { Support }\end{array}$} & Diameter $(\mathrm{cm})$ & 356. & 381 & 363 \\
\cline { 2 - 5 } & Thickness $(\mathrm{cm})$ & 34.3 & 53.3 & 8.9 \\
\hline
\end{tabular}

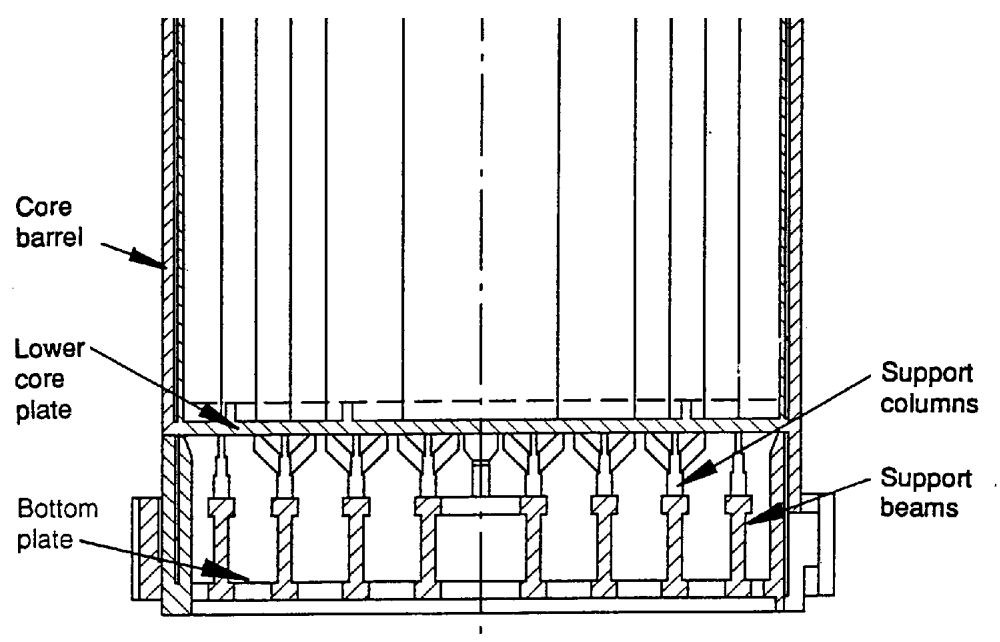

Figure 3. Waterford lower core plate assembly (Combustion Engineering).

\section{Boiling Water Reactor Designs}

The core plate in a BWR separates the core region from the lower plenum as shown in Figure 4. The primary functions of the core plate are (1) to provide lateral (but not vertical) support for the bottom of the fuel assemblies and (2) to provide a barrier that forces most of the upward-flowing coolant into the fuel assemblies. Without the core plate, the coolant would travel the path of least resistance outside the fuel assemblies in the interstitial region.

The weight of the core is supported by the bottom head (except for about $3 \%$ of the assemblies at the periphery of the core that are supported directly by the core plate). A group of four fuel assemblies sits on top of a fuel support piece which rests on top of a control rod guide tube. Each control rod guide tube is welded to the bottom head via a control rod drive (CRD) housing and a stub tube. Holes near the tops of the control rod guide tubes align with flow orifices in the fuel support pieces to provide coolant flow paths from the lower plenum into the bottom of each fuel assembly.

A more detailed drawing of a BWR core plate is provided in Figure 5. The core plate is fabricated from a 5.08-cm (2-in.) thick piece of stainless steel with large holes [27.94-cm (11-in.) diameter on 30.48$\mathrm{cm}$ (12-in.) centers] to accommodate the control rod guide tubes and small holes [5.08-cm (2-in.) 


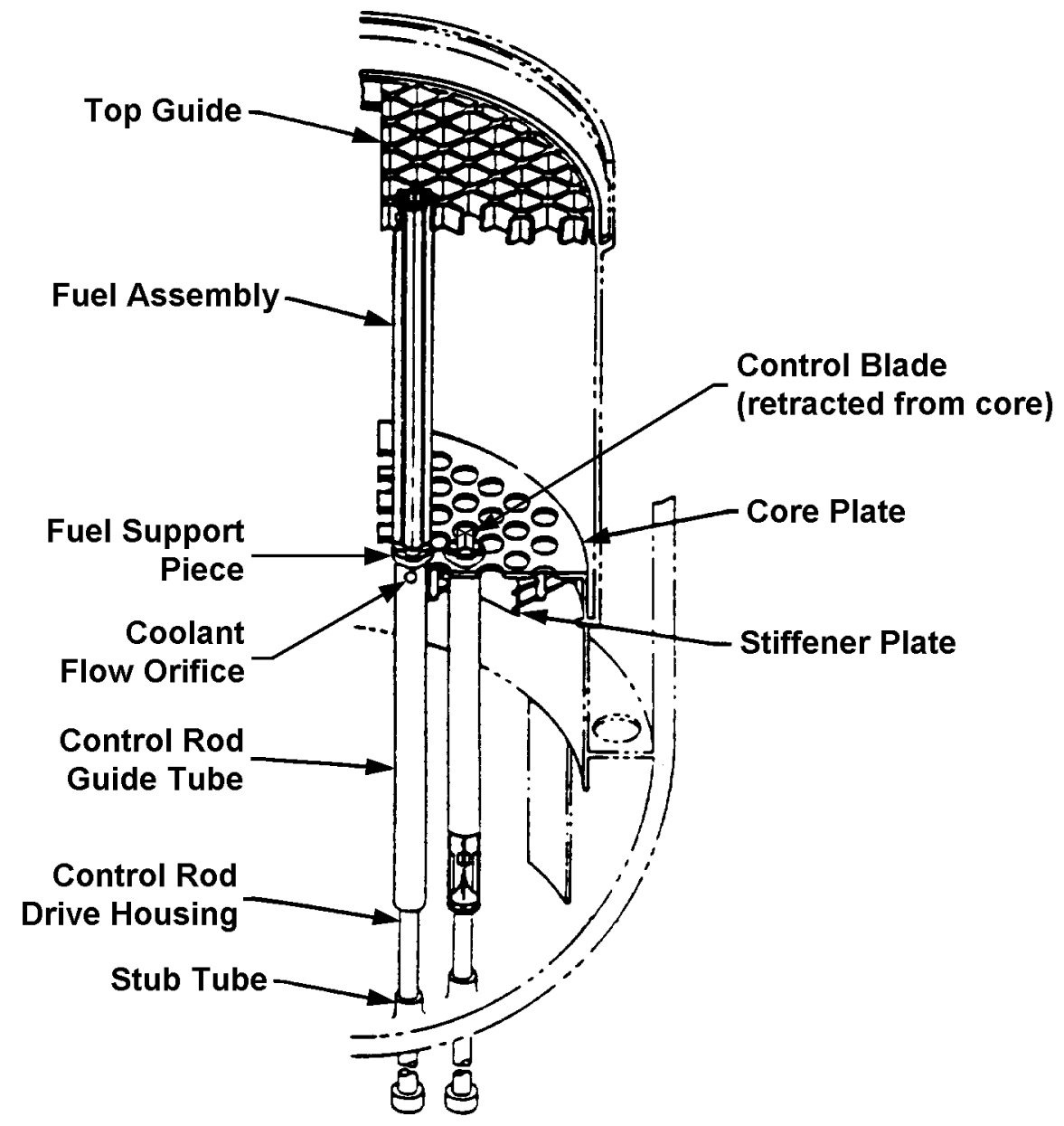

Figure 4. Position of core plate relative to other structures in BWR vessel.

diameter] for the instrument guide tubes. Vertical stiffener plates and perpendicular stiffener rods are located every $60.96 \mathrm{~cm}$ ( $24 \mathrm{in}$.) below the core plate to support the structure. The edge of the circular core plate assembly is bolted to a support ledge located between the lower shroud and the core shroud.

The other structures in the BWR core plate region illustrated in Figure 6 are also fabricated from stainless steel. The fuel support piece that sits on top of each control rod guide tube has four passages that direct coolant flow into the nose pieces at the bottoms of four fuel assemblies. There is also a cross-shaped opening in the center of each fuel support piece that allows the control blade to be inserted into and retracted from the core. During normal reactor operations, the control blades are fully retracted from the core as illustrated in Figure 4. After reactor scram during a severe accident, the control blades would be fully inserted into the core. 


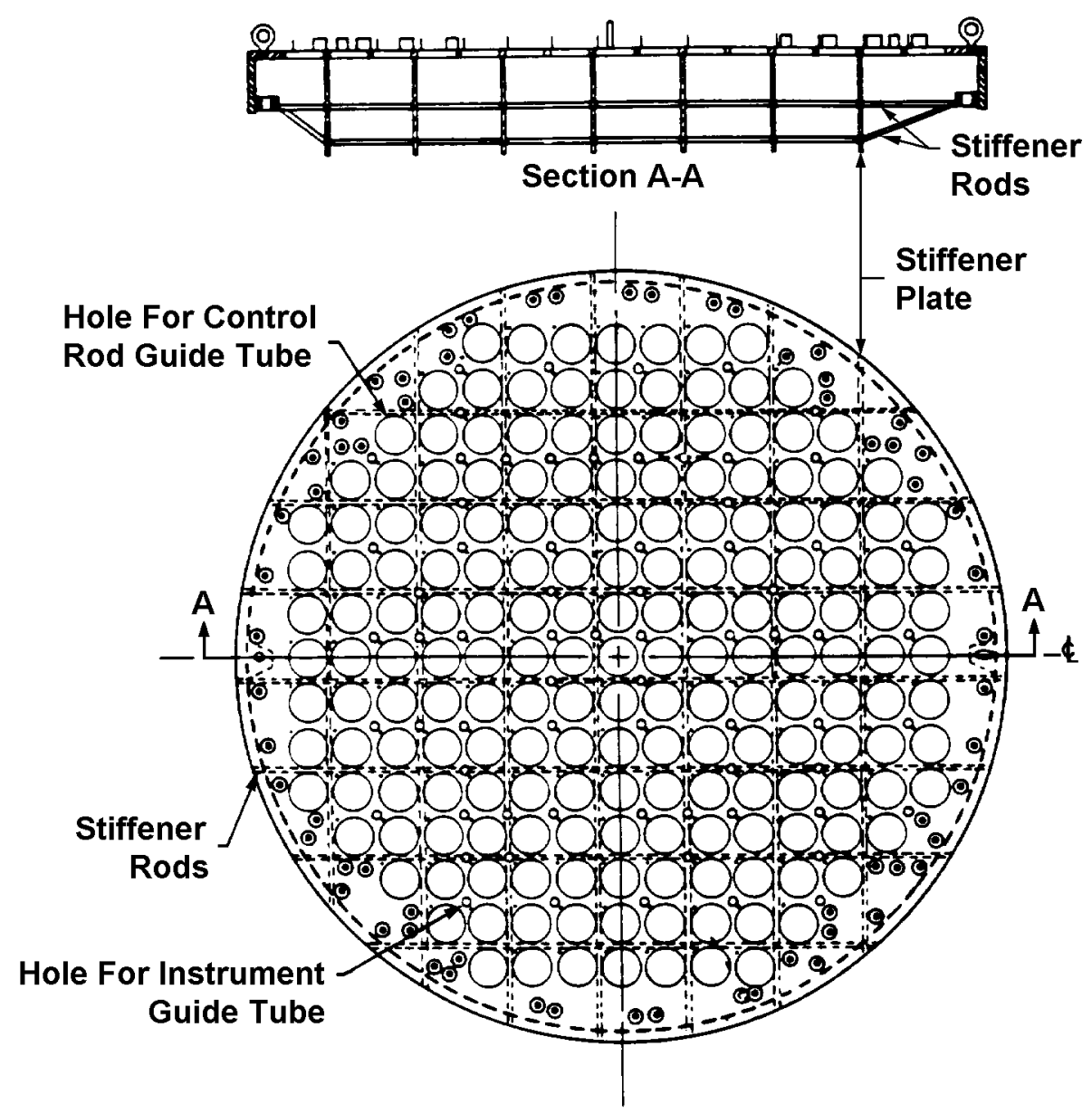

Figure 5. Top and side views of BWR core plate assembly. 


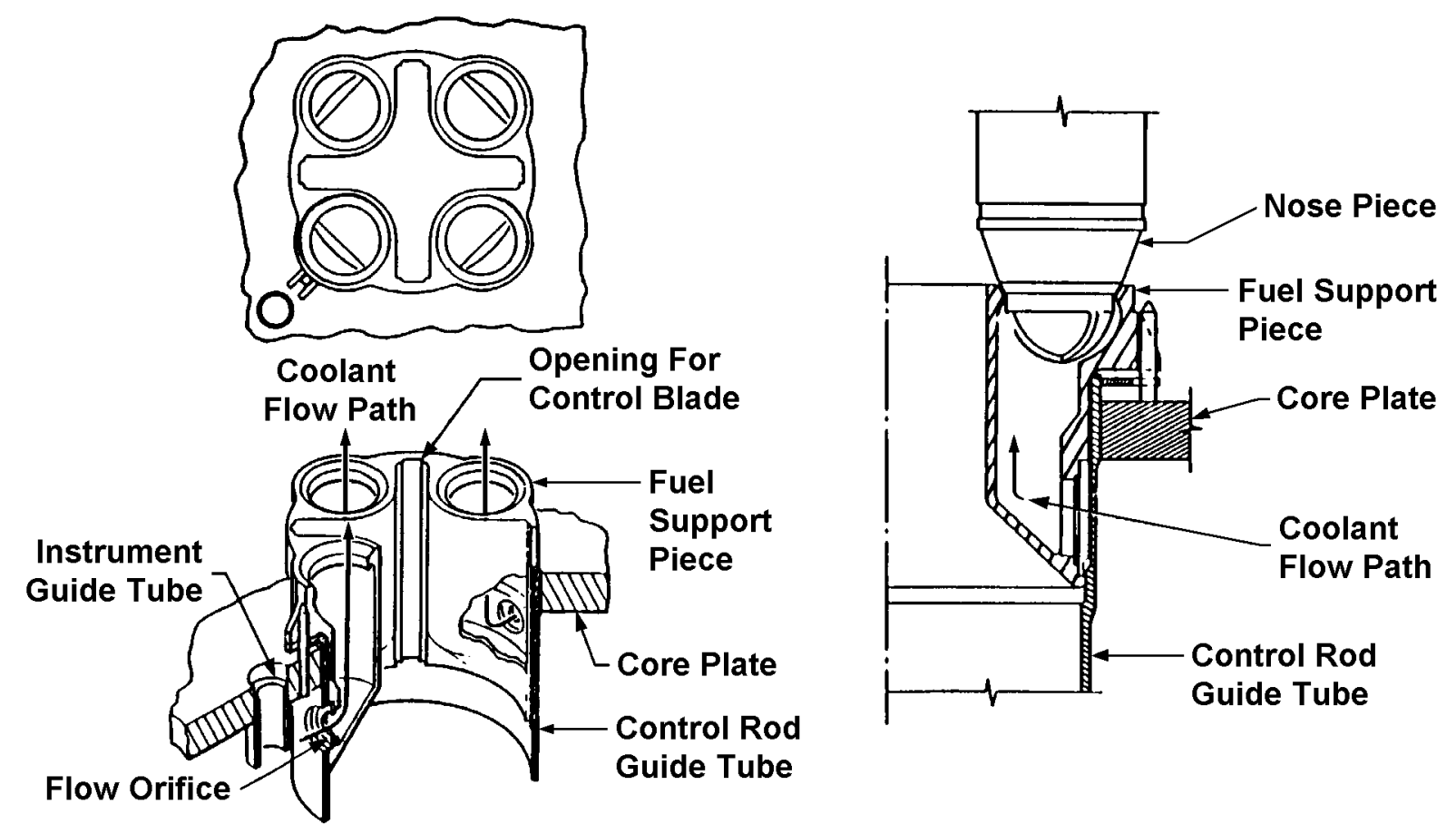

Figure 6. Detailed views of other structures located in BWR core plate region. 


\section{PHENOMENOLOGY}

This chapter will characterize the relocation and degradation processes that are anticipated in the core plate region during a severe accident, by summarizing the results of several SCDAP/RELAP5 accident simulations for both PWR and BWR plants. Also, test results are presented for the XR2-1 experiment (conducted at Sandia National Laboratories), which is the only experimental information available for the response of the core plate region to a severe accident. These simulations and experimental results should provide an estimate of the range of conditions which a core plate model would be expected to handle, as well as an estimate of the amount and type of debris that is expected to relocate downward from the core into the core plate region.

\section{Pressurized Water Reactor Processes}

The history of SCDAP/RELAP5 application to PWR analyses is extensive. Most recently it has been used to characterize the probability of containment failure by direct containment heating (DCH), and those analyses will be used to characterize the conditions the core plate model will be required to represent during a typical analysis. The descriptions of the transients provided here are intended to summarize a series of lengthy and well-documented analyses. For additional detail, please refer to the appropriate reference.

\section{Surry DCH Results}

The Surry DCH study ${ }^{8}$ was a best-estimate SCDAP/RELAP5 analysis of the Surry PWR during a TMLB' sequence without recovery and without operator actions. The analysis was designed to evaluate the behavior of the reactor coolant system (RCS) and the progression of core damage with seal leaks of 480 gpm per reactor coolant pump (RCP). The sequence of events for this analysis can be summarized as follows: The reactor scrammed and RCPs tripped due to the loss of AC power at TMLB' initiation (at $0 \mathrm{~s}$ ). Seal leaks of $21 \mathrm{gpm}$ per RCP were introduced at that time to simulate leakage associated with the loss of seal cooling that would accompany the loss of AC power. An initial RCS pressure reduction occurred because boiling on the SG secondary side was sufficient to remove core decay heat and cool the RCS. However, the steam generator (SG) heat sinks were not sustainable without feedwater, and the RCS pressure began to increase following SG dryout. The pressure increase terminated at the pressurizer PORV opening set point and a gradual RCS heatup and boiloff followed where PORV cycling provided pressure control between 15.8 and 16.3 MPa. When saturated conditions were reached at the RCPs, seal leaks were increased to $480 \mathrm{gpm}$ per RCP to simulate failures that could develop with two-phase flow across the seal faces.

Core decay heat was transported to the SGs by full loop natural circulation of liquid until vapor generated in the core had collected in the top of the SG U-tubes, preventing further liquid circulation. Energy dissipated through RCP seal leaks exceeded core decay heat after 8980 s. As a result, the RCS pressure dropped below the PORV set point, which ended further PORV cycling. The first core uncovery began at $8783 \mathrm{~s}$ and was complete by $10372 \mathrm{~s}$ as a result of boiling and venting through the RCP seals. By $8900 \mathrm{~s}$, voiding in the SG tubes and hot legs allowed development of hot leg countercurrent natural circulation. Heat transfer to the ex-vessel piping by the countercurrent flow produced a heatup and an associated creep rupture failure of the hot leg in the pressurizer loop at $22975 \mathrm{~s}$. A $0.150 \mathrm{~m}$ diameter break was introduced at the time of hot leg failure, allowing further RCS pressure reduction and injection of the remaining accumulator inventory. The accumulators emptied at $23200 \mathrm{~s}$, with a core collapsed liquid level 
$\sim 0.22 \mathrm{~m}$ below the top of the fuel rods. A second heatup and boiloff at low RCS pressure followed, with a second (and final) core uncovery completed at $24056 \mathrm{~s}$.

The first formation of an in-core molten pool occurred as a result of heating to ceramic melt conditions at $12213 \mathrm{~s}$. However, accumulator injections (starting at $12362 \mathrm{~s}$ ) delayed further melting until $27649 \mathrm{~s}$, when control rod absorber materials began to melt and relocate to the lower head. Core melting followed since accumulators (the only cooling water source) emptied by $23200 \mathrm{~s}$. The melt spread both axially and radially until the pool reached the core periphery at $32406 \mathrm{~s}$. At that time, the contents of the in-core molten pool (58 $648 \mathrm{~kg}$ of UO2, $14966 \mathrm{~kg}$ of ZrO2) was relocated to the lower head over a $60 \mathrm{~s}$ time period. Following the first core relocation to the lower head, a second relocation of molten materials (4976 kg of UO2 and $1170 \mathrm{~kg}$ of $\mathrm{ZrO} 2$ ) took place at $36260 \mathrm{~s}$. A summary of the lower head debris at the end of the simulation is provided in Table 2.

Table 2. Debris parameters during Surry DCH study.

\begin{tabular}{|c|c|}
\hline Lower Head Debris Characterization & \\
\hline \hline$A g-I n-C d$ & $1,923 \mathrm{~kg}$ \\
\hline $\mathrm{UO} 2$ & $63,624 \mathrm{~kg}$ \\
\hline $\mathrm{ZrO2}$ & $16,136 \mathrm{~kg}$ \\
\hline Maximum temperature & $3653 \mathrm{~K}$ \\
\hline Average molten temperature & $3303 \mathrm{~K}$ \\
\hline Molten Fraction & 0.70 \\
\hline
\end{tabular}

\section{Zion DCH Resi;ts}

The Zion DCH study ${ }^{9}$ was a best-estimate SCDAP/RELAP5 analysis of the Zion PWR during TMLB' sequences without recovery and without operator actions. The Zion transient was designed to be very similar as the Surry transient just described, but three cases of varying RCP seal leak rates were considered. The range of debris values from all three cases are presented in Table 3.

The behavior of the Zion PWR was as follows: The reactor scrammed and RCPs tripped due to the loss of AC power at TMLB' initiation (at $0 \mathrm{~s}$ ). Once again seal leaks of $21 \mathrm{gpm}$ per RCP were introduced at that time to simulate leakage associated with the loss of seal cooling that would accompany the loss of AC power. An initial RCS pressure reduction occurred because boiling on the SG secondary side was sufficient to remove core decay heat and cool the RCS. However, the SG heat sinks were not sustainable without feedwater. As a result, the RCS pressure began to increase following SG dryout (at 4800-5000 s). The pressure increase terminated at the pressurizer PORV opening set point, which was reached at $5680 \mathrm{~s}$ A gradual RCS heatup and boiloff followed with PORV cycling providing pressure control between 15.7 and 16.2 MPa. Saturated conditions were reached at the RCPs at $7466 \mathrm{~s}$. Seal leaks were increased to 480 gpm per RCP at that time to simulate failures that could develop with two-phase flow across the seal faces.

Core decay heat was transported to the SGs by full loop natural circulation of liquid until $7526 \mathrm{~s}$. By that time, vapor generated in the core had collected in the top of the SG U-tubes, preventing further liquid circulation. Energy dissipated through RCP seal leaks exceeded core decay heat by $8456 \mathrm{~s}$. As a result, the RCS pressure dropped below the PORV set point, which ended further PORV cycling. The pressure 
reduction resulting from RCP seal leak flows persisted until the initial accumulator pressure of 4.24MPa (and the associated injection) was reached at $12312 \mathrm{~s}$. The first core uncovery began at $8644 \mathrm{~s}$ and was complete by $10016 \mathrm{~s}$ as a result of boiling and venting through the RCP seals. By $8697 \mathrm{~s}$, voiding in the SG tubes and hot legs allowed development of hot leg countercurrent natural circulation. Heat transfer to the ex-vessel piping by the countercurrent flow produced a heatup and an associated creep rupture failure of the hot leg in the pressurizer loop at $20650 \mathrm{~s}$. A $0.166 \mathrm{~m}$ diameter break was introduced at the time of hot leg failure, allowing further RCS pressure reduction and injection of the remaining accumulator inventory. The accumulators emptied at $20920 \mathrm{~s}$, with a core collapsed liquid level $0.82 \mathrm{~m}$ below the top of the fuel rods. A second heatup and boiloff at low RCS pressure followed, with a second (and final) core uncovery completed at $21470 \mathrm{~s}$.

The first formation of an in-core molten pool occurred as a result of heating to ceramic melt conditions at $12169 \mathrm{~s}$. However, accumulator injections (starting at $12312 \mathrm{~s}$ ) delayed further melting until $26610 \mathrm{~s}$, when control rod absorber materials began to melt and relocate to the lower head. Core melting followed since accumulators (the only cooling water source) emptied by $20920 \mathrm{~s}$. The melt spread both axially and radially until the pool reached the core periphery at $29212 \mathrm{~s}$. At that time, the contents of the in-core molten pool (60 $290 \mathrm{~kg}$ of UO2 and $16690 \mathrm{~kg}$ of $\mathrm{ZrO} 2$ ) was relocated to the lower head over a 60 s time period (Note that some debris had accumulated from prior relocations of control rod materials.)

Table 3. Debris parameters during Zion DCH study.

\begin{tabular}{|c|c|c|}
\hline Core Plate Debris Characterization & Minimum & Maximum \\
\hline \hline$A g-I n-C d$ & $200(\mathrm{~kg})$ & $2350(\mathrm{~kg})$ \\
\hline$U O 2$ & $61040(\mathrm{~kg})$ & $82550(\mathrm{~kg})$ \\
\hline $\mathrm{Zr}$ & 0 & $452(\mathrm{~kg})$ \\
\hline $\mathrm{ZrO2}$ & $15770(\mathrm{~kg})$ & $20860(\mathrm{~kg})$ \\
\hline Maximum Temperature & $3775 \mathrm{~K}$ & $4108 \mathrm{~K}$ \\
\hline Average molten temperature & $3415 \mathrm{~K}$ & $3794 \mathrm{~K}$ \\
\hline Molten Fraction & .81 & 1.0 \\
\hline
\end{tabular}

\section{Boiling Water Reactor Processes}

This section describes the damage progression that is expected to occur in the BWR core plate region during a severe accident. First, the results of a severe accident simulation for the Browns Ferry BWR design are presented to provide an estimate of the amount and type of debris that is anticipated to relocate downward from the core into the core plate region. Refer to Reference 10 for a description of the SCDAP/RELAP5 input deck for Browns Ferry and for a more complete presentation of the predicted results. Then, some test results are presented for the XR2-1 BWR metallic melt relocation experiment conducted at Sandia National Laboratory, which is the only experimental information available for the severe accident response of the core plate region. 


\section{Browns Ferry BWR Results}

A SCDAP/RELAP5 calculation was performed for the Browns Ferry BWR design based upon a short-term station blackout (STSB) accident sequence. ${ }^{10}$ This section includes only the calculated results that are relevant to the structures in the core plate region. The initial condition for the Browns Ferry STSB accident simulation is steady-state reactor operation at full power. The STSB accident sequence is caused by a loss of off-site AC power combined with failure of the emergency diesel generators and is initiated in the SCDAP/RELAP5 simulation by: (1) loss of AC power to the recirculation pumps and the CRD cooling water pumps, (2) main steam isolation valve (MSIV) closure, (3) reactor scram, and (4) loss of the turbinedriven feedwater pumps followed by feedwater coast-down. Throughout the duration of the STSB accident sequence, all sources of Emergency Core Cooling System (ECCS) injection are unavailable. The calculated results for the STSB accident simulation are summarized in the following discussion.

After reactor scram and MSIV closure at the beginning of the accident, steam continues to be generated within the vessel because of the decay power. This steam is released to the suppression pool by the safety/relief valves (SRVs) that open and close to maintain the vessel pressure between 6.516 MPa (945 psia) and 7.688 MPa (1115 psia). As steam is released from the vessel, the vessel water level falls and reaches the top of active fuel at 3,502 s after scram (see Table 4). When the water level reaches one-third of the active fuel height at 5,922 s, the reactor operators initiate the Automatic Depressurization System (ADS). The vessel water inventory flashes to steam during the depressurization, stabilizing in the lower 
plenum at a level well below the core plate; thus the core and core plate regions are dry prior to the beginning of any structural degradation.

Table 4. Predicted event times for Browns Ferry STSB accident

\begin{tabular}{|c|c|c|c|c|}
\hline Description of Event & \multicolumn{4}{|c|}{$\begin{array}{c}\text { Time After Scram } \\
\text { (s) }\end{array}$} \\
\hline Short-term station blackout accident initiation & \multicolumn{4}{|c|}{0} \\
\hline Collapsed water level at top of active fuel & \multicolumn{4}{|c|}{3,502} \\
\hline \multirow{2}{*}{$\begin{array}{l}\text { ADS initiation (collapsed water level at one-third } \\
\text { active fuel height) }\end{array}$} & \multicolumn{4}{|c|}{5,922} \\
\hline & $\begin{array}{c}\text { Ring } 4 \\
\text { (periphery) }\end{array}$ & Ring 3 & Ring 2 & $\begin{array}{l}\text { Ring } 1 \\
\text { (center) }\end{array}$ \\
\hline First control blade liquefaction $(1505 \mathrm{~K})$ & 10,068 & 8,340 & 8,004 & 7,740 \\
\hline $\begin{array}{l}\text { First relocation of molten metallic material below } \\
\text { bottom of active fuel }\end{array}$ & 11,556 & 8,400 & 8,124 & 7,860 \\
\hline $\begin{array}{l}\text { First blockages between control blades and channel } \\
\text { boxes }\end{array}$ & 11,763 & 8,643 & 8,388 & 7,992 \\
\hline First fuel cladding relocation (2200 K) & 12,060 & 9,120 & 8,410 & 8,348 \\
\hline $\begin{array}{l}\text { Molten ceramic pool (occupying } 3 \text { of } 4 \text { core radial } \\
\text { rings) begins to relocate downward from core } \\
\text { region into lower plenum }\end{array}$ & \multicolumn{4}{|c|}{12,038} \\
\hline Remaining water evaporates from lower plenum & \multicolumn{4}{|c|}{13,692} \\
\hline Creep rupture failure of bottom head & \multicolumn{4}{|c|}{22,095} \\
\hline
\end{tabular}

After the core becomes uncovered, it begins to heat up. The radial power distribution is represented in the Browns Ferry simulation by dividing the core into four radial rings identified as Rings 1 (center of core) through 4 (periphery of core). Control blade liquefaction begins in Ring 1 at 7,740 s (refer to Table 4) when the control blades reach a temperature of $1505 \mathrm{~K}$. The molten control blade material relocates downward and either solidifies at lower elevations in the core or falls below the bottom of active fuel (beginning in Ring 1 at 7,860 s). When sufficient freezing occurs, blockages form between the locally intact control blades and the outer surfaces of the channel boxes (beginning in Ring 1 at 7,992 s). The portion of the fuel cladding which has not oxidized begins to relocate in Ring 1 at 8,348 s when the cladding oxide layer fails at a user-specified temperature of $2200 \mathrm{~K}$. The degradation processes are similar in Rings 2 through 4, except they occur at progressively later times because the decay power is smaller near the periphery of the core.

Some of the control blade/channel box material that initially solidifies in the lower core region melts again and also relocates downward below the bottom of active fuel. Because the current version of SCDAP/RELAP5 does not represent the severe accident response of the core plate region structures, this molten metallic material falls directly into the lower plenum to form a debris bed (represented by the COUPLE module) with the height shown in Figure 7. The molten metallic material falls below the bottom 
of active fuel at a fairly steady rate for a 1,968-s period from 7,860 to 9,828 s after scram. At the end of this period, a total of $13,700 \mathrm{~kg}$ of metallic material has relocated from the core region, which is more than the total mass of the Browns Ferry core plate assembly $(9,300 \mathrm{~kg}$ ). Therefore, it is expected that the molten metallic material (at temperatures $>1500 \mathrm{~K}$ ) relocating below the bottom of active fuel should cause significant heating of the core plate and surrounding structures that is not currently represented in SCDAP/ RELAP5 (these structures are currently represented by RELAP5 heat structures and their predicted temperatures never exceed $500 \mathrm{~K}$ ).

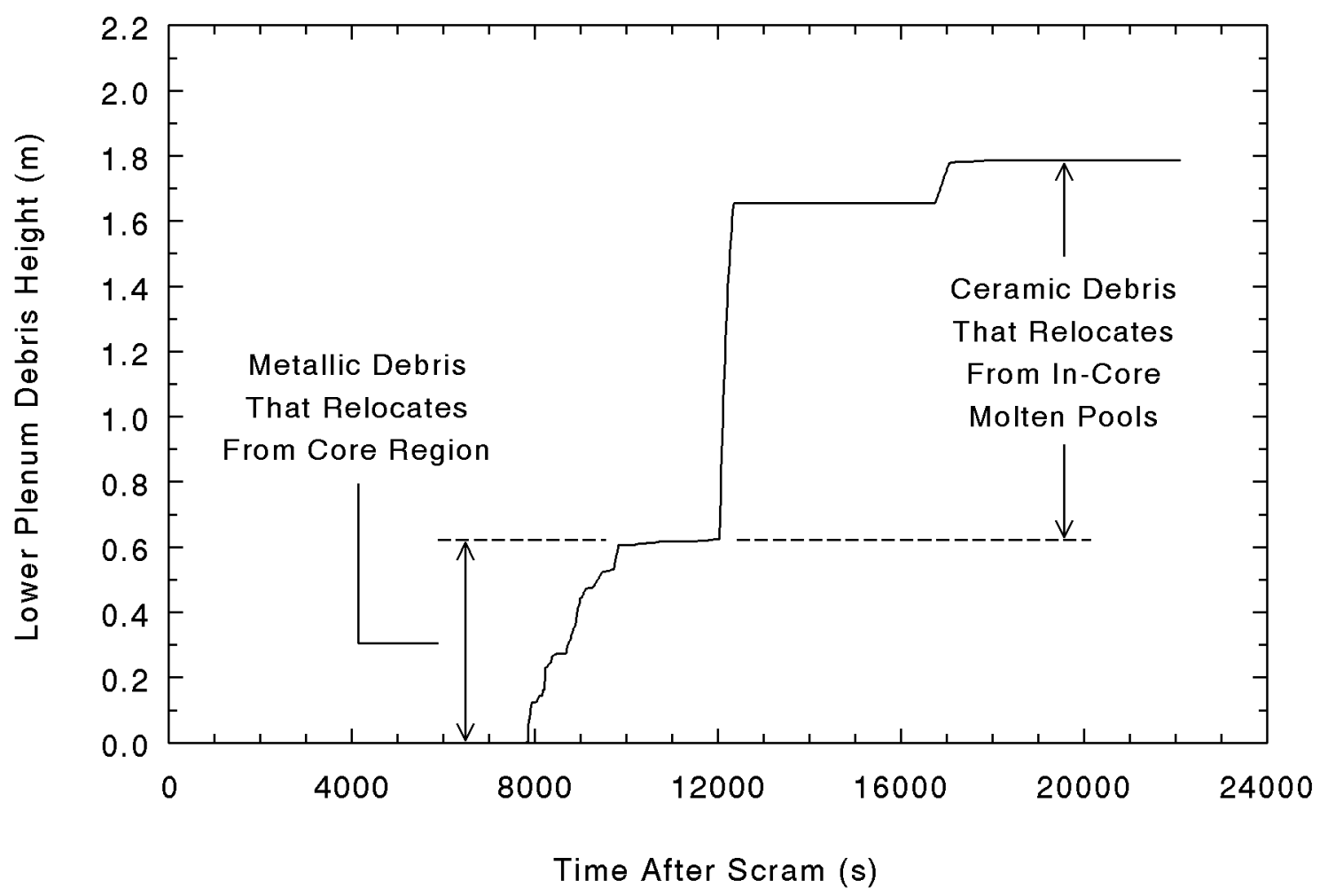

Figure 7. Predicted lower plenum debris height for Browns Ferry STSB accident.

As heating of the core continues, fuel rod degradation leads to formation of a large molten ceramic pool that occupies three of the four core radial rings. This molten pool is held in place by a frozen crust that can propagate both axially and radially into any surrounding porous debris. Spreading of the molten ceramic pool occurs when the heat flux from the molten pool to the inside surface of the crust is greater than the heat flux from the outside surface of the crust to the coolant. At 12,038 s, the in-core molten pool, which is at a temperature of $2934 \mathrm{~K}$, is calculated to begin relocating downward into the lower plenum (this relocation process takes $300 \mathrm{~s}$, refer to Figure 7). The printed output for the Browns Ferry STSB accident simulation indicates that the supporting crust fails in Ring 1 because the crust propagates downward past the bottom of active fuel. The current in-core molten pool model in SCDAP/RELAP5 does not account for the structures in the core plate region. During an actual severe accident, however, it is expected that the molten pool would continue to spread down towards the core plate and the stainless steel structures in the core plate region would quickly melt unless there is a large cooling ate at the outside surface of the crust supporting the molten pool. 
A second molten ceramic pool forms in the core region and begins to relocate downward into the lower plenum at 16,747 s. At the end of the Browns Ferry STSB accident simulation (creep rupture failure of the bottom head occurs at 22,095 s), a total of 159,644 kg of debris has fallen into the lower plenum. This debris consists of 7,662 $\mathrm{kg}$ of control blade material, 17,859 $\mathrm{kg}$ of $\mathrm{Zr}, 6,825 \mathrm{~kg}$ of $\mathrm{ZrO}_{2}$, and 127,298 $\mathrm{kg}$ of $\mathrm{UO}_{2}$.

\section{XR2-1 Experiment Results}

The only experimental information available for the behavior of the core plate region structures during a severe accident is from the XR2-1 BWR metallic melt relocation experiment performed at Sandia during October 1995. ${ }^{11}$ The purpose of that experiment was to investigate the damage progression and the material relocation processes in the lower portion of a dry BWR core during the early phase of a severe accident (such as an STSB accident). The term "early phase" is used to refer to the period of the accident when the metallic structures (both stainless steel and Zircaloy) are melting and relocating. The XR2-1 test did not address the "late phase" of a severe accident after the ceramic fuel pellets begin to melt.

The XR2-1 test assembly (see the cross-sectional view in Figure 8) employed full-scale, prototypical BWR components and simulated a region from $50 \mathrm{~cm}$ above the bottom of active fuel downward to $20 \mathrm{~cm}$ below the core plate. The test assembly included portions of (1) fuel rods with depleted $\mathrm{UO}_{2}$ pellets, (2) channel boxes, (3) nose pieces, (4) control blades with velocity limiters, (5) fuel support pieces with coolant flow passages, (6) control rod guide tubes, and (7) the core plate. The test package was surrounded by $5.08 \mathrm{~cm}\left(2 \mathrm{in}\right.$.) of $\mathrm{ZrO}_{2}$ fiber insulation to minimize radial heat losses.

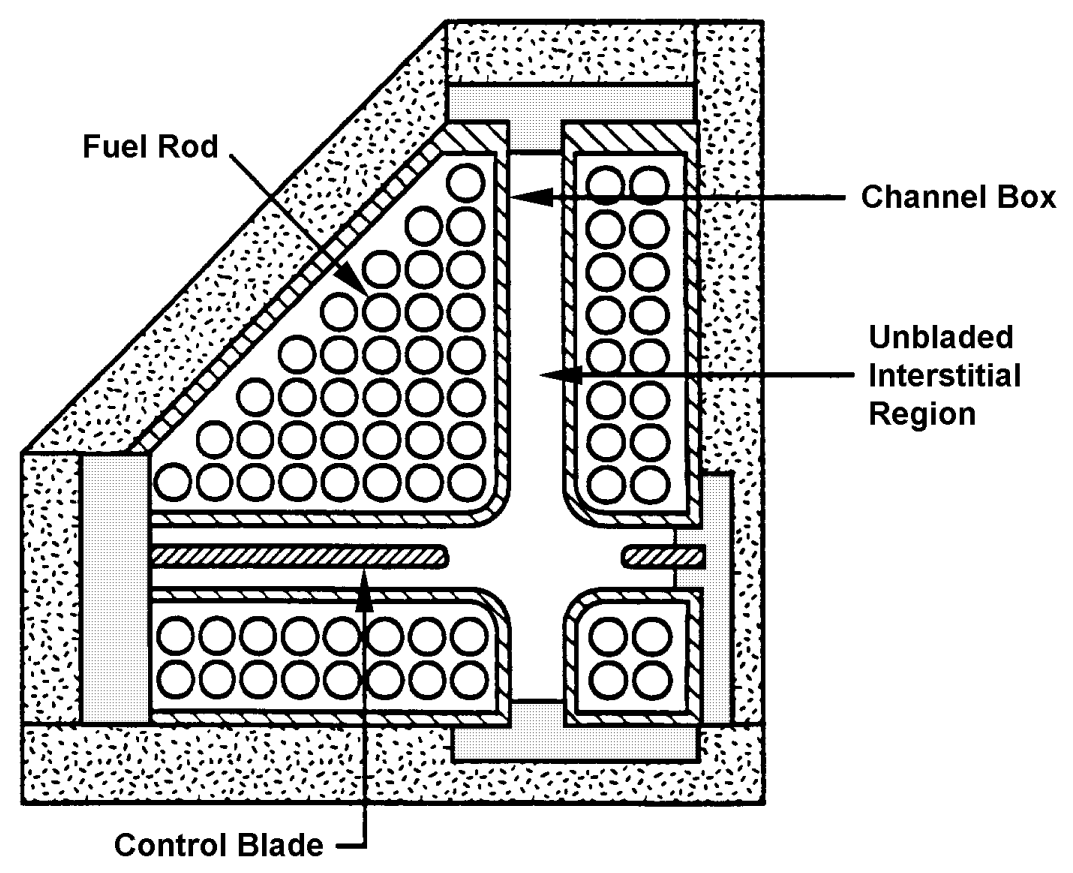

Figure 8. Cross-sectional view of XR2-1 test assembly 
After preheating the XR2-1 test assembly to achieve a temperature gradient from about $1600 \mathrm{~K}$ (at the top of the assembly) to $580 \mathrm{~K}$ (at the core plate), molten metallic material was delivered into the top of the assembly using a wire feeding/melting system. First, $18 \mathrm{~kg}$ of a molten stainless steel/ $\mathrm{B}_{4} \mathrm{C}$ eutectic mixture was delivered at a steady rate during a 1,000-s period. Then, $35 \mathrm{~kg}$ of molten Zircaloy was delivered at a steady rate during a subsequent 950 -s period. The stainless steel/ $\mathrm{B}_{4} \mathrm{C}$ feed points ( 10 total) were distributed above the control blades in the test assembly, and the Zircaloy feed points (31 total) were distributed above the fuel rods and the channel boxes.

The general behavior observed during the XR2-1 experiment was that the molten metallic material relocated downward and solidified when it flowed over cooler surfaces at lower elevations in the test assembly. After sufficient freezing occurred, localized blockages formed and caused additional molten material to pool on top of these blockages. As top-to-bottom heating of the test assembly continued, however, the blockages remelted, and the localized pools drained suddenly and flowed farther down into the test assembly. These sudden drainages caused some of the molten metallic material to bypass the core plate region completely and relocate downward past the bottom of the test assembly into a catch basin.

The Sandia staff identified three primary drainage paths as shown in Figure 9. The first drainage path was from the portion of the interstitial region where a control blade is inserted into the core, through the cross-shaped opening in the center of a fuel support piece (refer to Figure 6) and past the control blade velocity limiter inside a control rod guide tube. The second drainage path was from the unbladed portion of the interstitial region onto the top of the core plate. During the XR2-1 test, considerable inventory accumulated on the core plate, and some of that molten material flowed over the top of the fuel support pieces and contributed to the first drainage path. The third drainage path was from the fuel bundle region inside a channel box, through the nose piece at the bottom of a fuel assembly, and through the coolant flow passage of a fuel support piece (refer to Figure 6).

The Sandia staff determined that structural degradation in the upper half (i.e., the rodded region) of the XR2-1 test assembly was significantly accelerated by material interactions. First, the Zircaloy channel box walls were destroyed by aggressive eutectic reactions with the molten control blade material. Subsequently, when molten Zircaloy was being delivered into the top of the assembly, the upper half of the fuel rods were stripped of their cladding, and the fuel pellet stacks collapsed to form regions of porous debris.

Below the rodded region, the stainless steel structures retained their geometric integrity during the XR2-1 experiment. Although there were no outright failures of the nose pieces, fuel support pieces, or the core plate, about $75 \%$ of the total molten metallic inventory $(53 \mathrm{~kg}$ of melted wire plus $9 \mathrm{~kg}$ of melted structures) relocated below the core plate through existing drainage paths. At the end of the test, this relocated material was located on top of the velocity limiters ( 35\% of total), inside the coolant flow passages at the bottom of the fuel support pieces ( $10 \%$ of total), and in the catch basin below the test assembly ( $\sim 30 \%$ of total). The balance of the molten metallic inventory ( $\sim 25 \%$ of total) formed noncoherent localized blockages in the region on top of and just above the core plate. The molten material that drained into and through the core plate region heated the core plate from an initial value of $580 \mathrm{~K}$ to about $1150 \mathrm{~K}$ at the end of the test. 


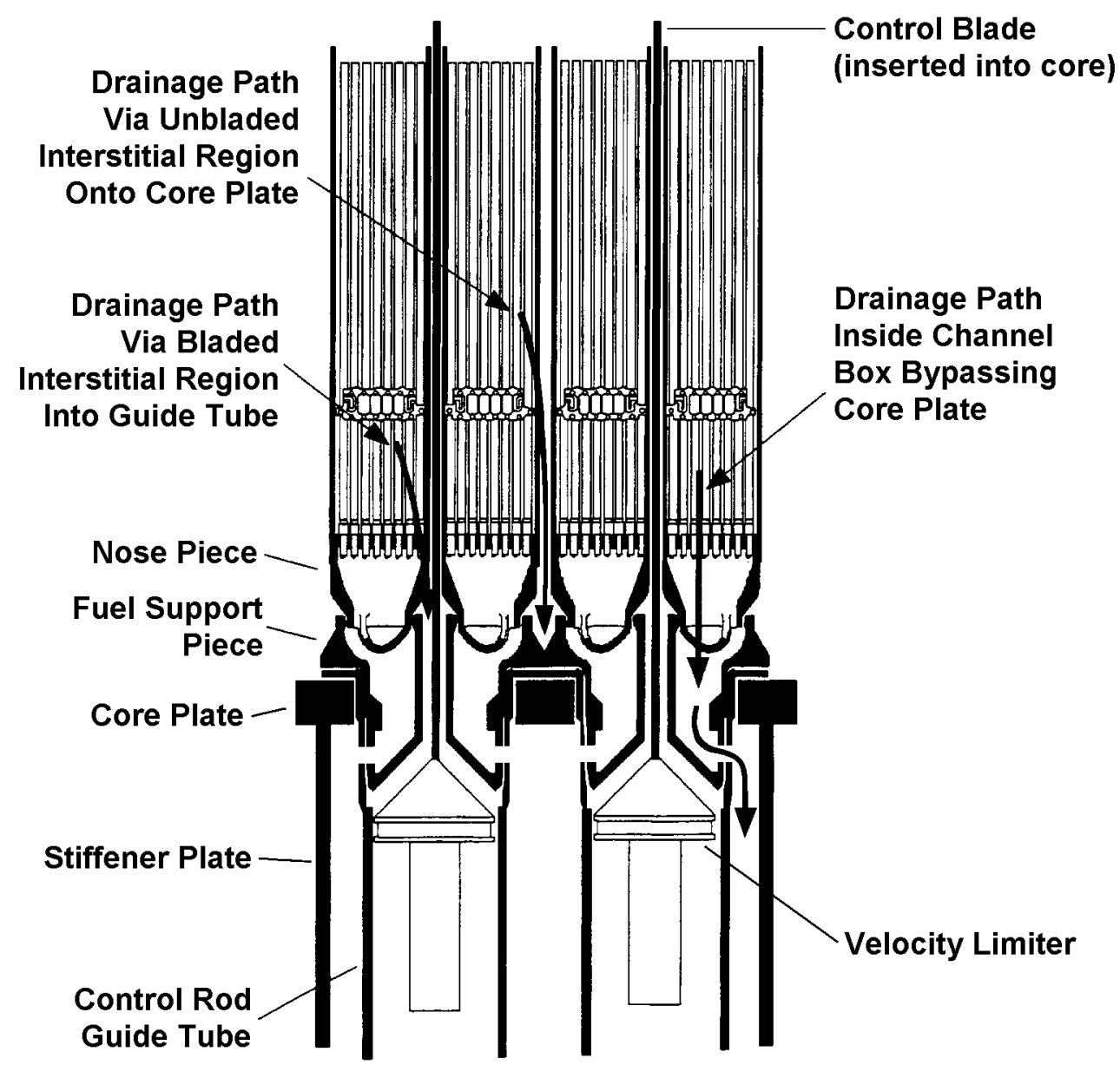

Figure 9. Drainage paths for molten metallic material during the XR2-1 experiment.

\section{Summary of Debris Characterization}

The experiment and analyses which have been summarized here indicate that relocation, whether from a PWR or BWR core, may occur in two stages. These stages are differentiated by the source and composition of the debris delivered to the lower core plate. The first stage consists of metallic debris and the second consists of a composite, primarily ceramic in nature, of $\mathrm{UO}_{2}, \mathrm{ZrO}_{2}$, and metals.

In the first stage, the control rods and other metallic structures within the core, melt, relocate, and refreeze in a lower/cooler region of the core. Then in a series of melt/relocate/refreeze cycles, these materials continue to move until they drop below the bottom of the active core. The debris state at the time it arrives at the core plate region is then a composite of primarily metallic materials, with a total mass on the order of 1-14 metric tons. This material is expected to be at approximately it's melting point, carrying little superheat, and will likely be completely molten. This material is expected to arrive at the core plate over a time span of thousands of seconds.

In the second stage, the core materials have melted and formed an in-core molten pool. This pool then gradually moves through the core region, both radially and axially, until it reaches either the periphery of the core or the bottom of the active core. At that time, the crust of the molten pool will fail and the 
molten contents of the pool will relocate to the core plate region over a relatively short time frame. This material will consist of a composite of $\mathrm{UO}_{2}, \mathrm{ZrO}_{2}$, and metals, and may have a total mass in the range from of 80 to 130 metric tons. The material will be non-homogeneous, and may only be $70 \%$ molten, with entrained solids. The average molten material temperatures will be close to the melting temperature of $\mathrm{UO}_{2}$, although highly localized regions may be as high as 3900-4000 K. 


\section{CORE PLATE MODEL DESCRIPTION}

One of the goals for developing a core plate model has been to maximize the use of existing models within SCDAP/RELAP5. Based upon discussions between the NRC Technical Monitor, the SCDAP development staff at INEEL, and the BWR model development staff at ORNL, several modeling options have been identified: (1) utilize the existing lower plenum debris model (COUPLE), (2) modify the existing upper plenum structure model, or (3) develop a completely new core plate model. Development of a new model was quickly eliminated because it was judged to be too costly.

In a typical SCDAP/RELAP5 simulation, the COUPLE module is utilized to represent the hemispherical region of the bottom head and any lower plenum debris. The user defines a two-dimensional finite-element mesh using cylindrical coordinates (radius and elevation). Each element in the mesh can be specified as either a solid material (e.g., carbon steel for the bottom head) or debris (initially filled with water). In theory, a single COUPLE mesh could be defined that extends from the bottom head upward to the bottom of the active core, including the core plate region. After extensive discussions, it was concluded that, although this method could provide a satisfactory representation of the thermal response of the core plate, the resources necessary to model the potentially intricate geometry and the damage progression expected to occur in the core plate region would also be too costly.

The upper plenum structure model in SCDAP/RELAP5 (described more completely in Reference 1) has many of the features needed for representation of the core plate region. This model includes calculations for heating (by convective heat transfer from the coolant), oxidation, melting, downward relocation, and solidification of pure stainless steel structures. The upper plenum structure model is based upon a slab geometry with rectangular coordinates and provides the user with sufficient flexibility to allow representation of a wide range of geometric configurations. Although core plate region structures are relatively complex, a slab geometry can be used to represent their thermal masses and heat transfer characteristics by using equivalent dimensions. This approach was judged to be the most economical way for modeling the damage progression that is expected to occur in the core plate region. The model represents the core plate region structures during the early phase of a severe accident through the phases of metallic and ceramic melting and relocation. Modifications to the core debris and molten pool models were also required to represent the core plate region during the late phase of a severe accident.

\section{General Approach}

The approach used in the core plate model was as follows:

The existing mass transfer of molten material from core region to lower head was redirected to first deliver the material to the core plate model. Material which relocates beyond the boundary of the core region will be assumed to be relatively viscous, and therefore will be allowed to free-fall to the core plate, where it will be assumed to have zero velocity and momentum. The code user has the capability of defining a flow path, expected to be along the core periphery, which will allow relocating material to bypass the core plate and fall directly into the vessel head. The structure of the core plate region will be represented with a combination of plates, similar to the upper plenum structure model, except that the plates may have penetrations. There is the capability of partitioning the area of the core plate model to represent those sections of the plate which are under one or more annular core rings. 
Material which rests on the horizontal surfaces will interact thermally with the core plate. Molten material will has the possibility of forming a crust on the plate if sufficient cooling occurs. The molten material will self-level within an annular ring, and no transfer of material from one annular ring to another will occur until a threshold height is exceeded. The core plate may melt, either partially or fully, to increment the metallic mass delivered to the lower plenum, and thermal failure (melting) of the plate is considered.

Molten material which lies over a core plate penetration will begin to relocate downward. If the material is metallic, a crust may form on the walls of the penetration and will have the capability of thickening until the penetration is blocked. If the material is primarily ceramic, no crust will form, but a slurry of two phase material will penetrate the core plate, until blockage is predicted to occur. In the event the material is predicted to relocate past the core plate, it will be passed to the fuel-coolant interaction (FCI) model.

\section{Modifications To Code Architecture}

Modifications to the architecture of the SCDAP/RELAP5 code occurred in three areas. These areas are:

\section{Input Logic}

Two new subroutines were added, rplate and iplate, which are called sequentially by the 'rscdap' routine, and read lower core plate input and initialize the data base, respectively. This data base is described in Table 5.

Table 5. Lower Core Plate Database Description

\begin{tabular}{|c|c|c|}
\hline Variable & Description & Units \\
\hline saplt & Surface Area of annular ring of plate & $m^{2}$ \\
\hline templt & Temperature at each node of each ring of each plate & $K$ \\
\hline pltdeb & Mass of each debris specie in each ring of each plate & $k g$ \\
\hline debtmp & Temperature of molten debris in each ring of each plate & $K$ \\
\hline thmov & Threshold height for radial relocation of debris & $m$ \\
\hline pltdt & $\begin{array}{c}\text { Mass of each debris specie delivered to each ring of each plate } \\
\text { during this time step }\end{array}$ & $k g$ \\
\hline enrdt & $\begin{array}{c}\text { Energy of each debris specie delivered to each ring of each } \\
\text { plate during this time step }\end{array}$ & $j$ \\
\hline mplt & Total mass of metal in each ring of each plate & $k g$ \\
\hline qplate & Heat flux to/from each side of each ring of each plate & $w / m^{2}$ \\
\hline plthk & Plate thickness of each ring of each plate & $m$ \\
\hline cpmap & Mapping between core components and plate regions & \\
\hline
\end{tabular}


Table 5. Lower Core Plate Database Description

\begin{tabular}{|c|r|l|}
\hline Variable & Description & Units \\
\hline \hline nring & Number of rings in each plate & \\
\hline nplate & Number of plates defined & \\
\hline srcplt & Location of source of debris for each ring of each plate & \\
\hline pltlnk & Type of source for each plate & \\
\hline ncnod & Number of conduction nodes for each ring of each plate & \\
\hline implt & Material index for each node of each ring of each plate & \\
\hline
\end{tabular}

\section{SCDAP Transient Logic}

Modifications to the transient portion of the code were extensive, and are shown in Figure 10. These modifications consisted primarily of

- Moving the upper plenum structure logic from late in the 'scdprh' routine, just before the call to the hydodynamic solution, to the 'scdad7' routine, just prior to the calculation of core slumping. This enabled the upper plenum structure model to have an impact on the slumping calculations.

- $\quad$ The calculation of material being relocated due to user-defined slumping was moved from the COUPLE module to the SCDAP routine 'scdad7', just prior to the call to the lower core plate model. This allowed the core plate model to experience user-defined slumping.

- $\quad$ The entire approach and data base for calculation of relocating material was modified. Rather than a single set of scalar variables which accumulated the energy and mass removed from the core region, a table of slumping periods was established, to track not only the specie mass, but also the source and location of each slump.

\section{COUPLE Logic}

The COUPLE module was modified to accept data from the core plate model, to eliminate userdefined slumping logic (now done in slmpdt), and to implement data connections between the core plate model and the Fuel-Coolant Interaction model developed previously.

\section{Lower Core Plate Model}

The model for the lower core plate includes generalized features that allow a single model to represent a range of geometric configurations. The user divides a core plate structure into a series of horizontal plates at different axial levels, with each plate having a bottom and top surface. The temperature gradient through each plate is represented by one or more conduction nodes. Conduction and other heat transfer processes are modeled in a direction perpendicular to the structure orientation.

The model is based on a slab geometry with rectangular coordinates, with the physical dimensions specified by the user at each axial level. A structure interacts with hydraulic volumes at both the bottom 


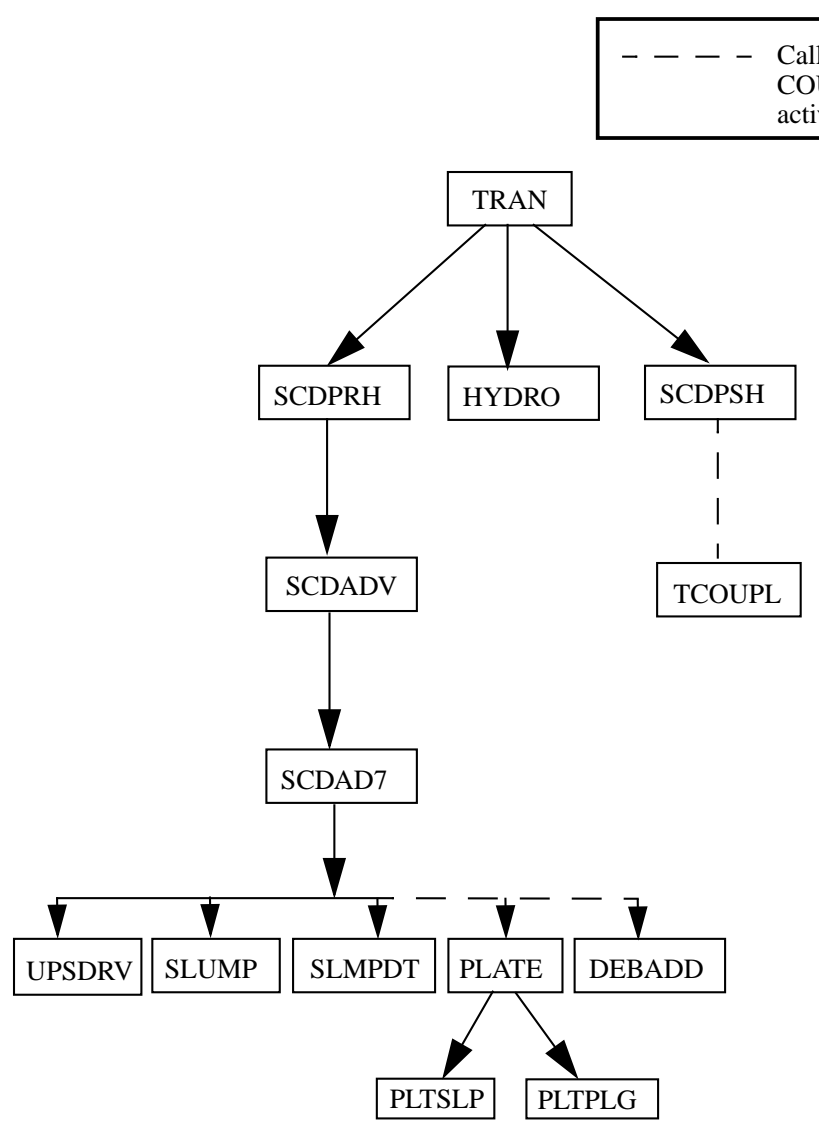

Figure 10. Architecture of material relocation subroutines

and top surfaces of the structure. The model is solved based upon the premise that each plate consists of a single user-specified material with a unique melting temperature. Because the structures have no internal heat sources, all heating and melting occurs at the outer surfaces. As a structure melts, molten material should not become superheated to any significant extent because either (1) the molten material will quickly relocate to a lower elevation or below the bottom of the structure or (2) more of the underlying solid structure will melt.

\section{Energy/Conduction Equation With Melting}

The differential equation for 1-D conduction heat transfer with melting is non-linear and requires a specialized solution method to account for the heat of fusion. A two-step process is applied in the described model. First, the conduction equation is solved without consideration of melting using an implicit solution method to ensure numerical stability. Then, if melting occurs during the timestep, the conduction solution is repeated to account for the change of phase.

A finite difference formulation in terms of the nodal temperatures is used to model the thermal response of an upper plenum structure. Using the nomenclature defined in Figure 11, the energy/ conduction equation for the first node (left side of Figure 11) is: 


$$
\operatorname{MC} 1\left(\mathrm{TS} 1_{\text {new }}-\mathrm{TS} 1_{\mathrm{old}}\right)=\frac{\mathrm{TCL}-\mathrm{TS} 1_{\text {new }}}{\mathrm{RC} 1}+\frac{\mathrm{TS} 2_{\text {new }}-\mathrm{TS} 1_{\text {new }}}{\mathrm{R} 12}+\mathrm{QOL}+\mathrm{QSL}
$$
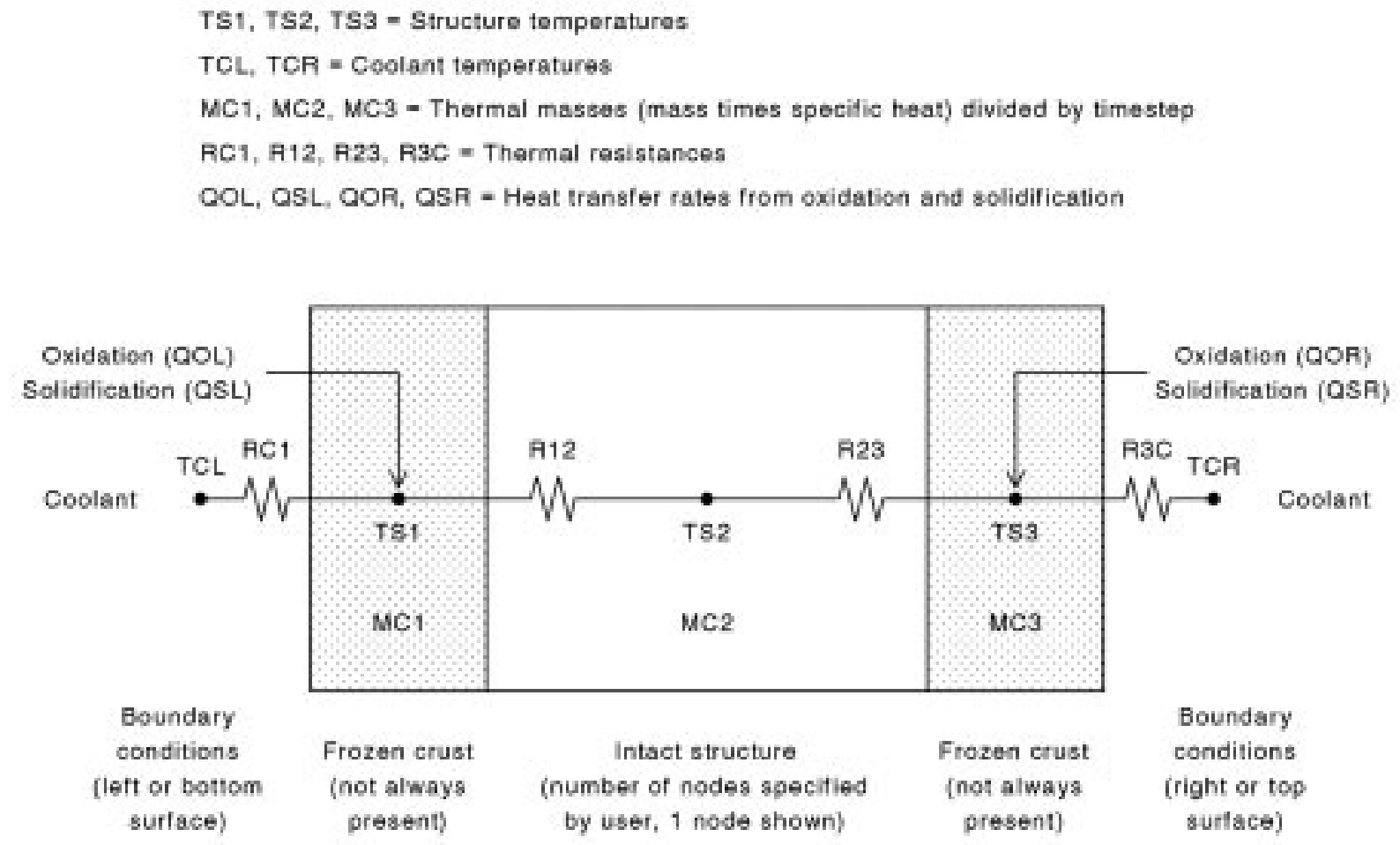

Figure 11. Nomenclature for solution of 1-D heat conduction equation at each axial level.

When similar finite difference equations are written for the other nodes, they form a linear system of algebraic equations with a tridiagonal arrangement:

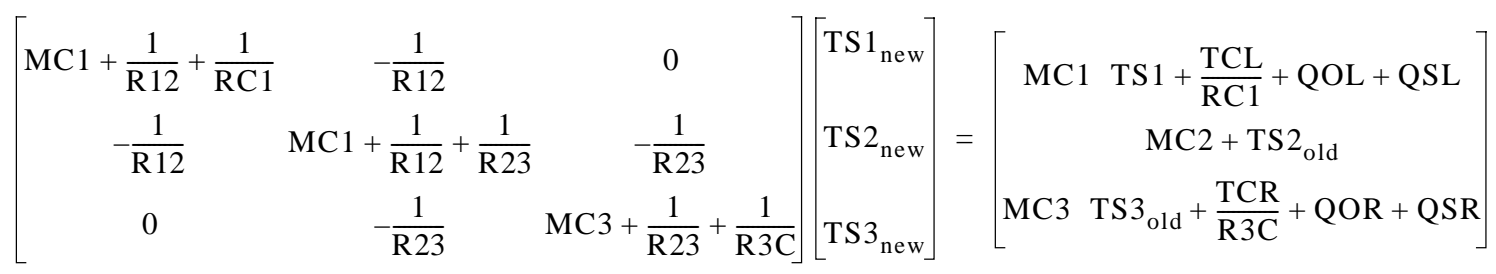

Material properties (specific heat, etc.) for the matrix elements are obtained from the MATPRO library. The nodal temperatures at a new time ( $\mathrm{TS} 1_{\text {new }}$, etc.) are calculated simultaneously from the temperatures at the previous time (TS1 $1_{\text {old }}$, etc.) using standard matrix methods.

The implicit solution method for the conduction equation involves a single iteration during a time step to account for any melting. The temperatures of the boundary nodes at a new time are compared with the melting temperature of stainless steel. If the new temperature of a boundary node is greater than the 
melting temperature, then that node is removed from the calculation and treated as a constant-temperature conduction boundary condition for the adjacent node. For example, if the above matrix solution predicts $\mathrm{TS} 1_{\text {new }}>\mathrm{TS} 1_{\text {melt }}$, then the first equation is removed from the matrix and $\mathrm{TS} 1_{\text {new }}=\mathrm{TS} 1_{\text {melt }}$ for the second equation:

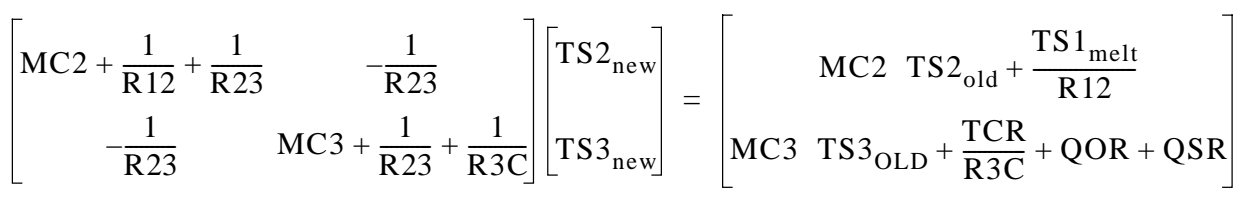

The implicit solution for the time step is then repeated to determine the new temperatures of the remaining nodes. The conduction/energy equation for the melting boundary node is used to determine the melting heat transfer rate:

$\mathrm{QMELT}-\frac{\mathrm{TCL}-\mathrm{TS} 1_{\text {melt }}}{\mathrm{RC} 1}+\frac{\mathrm{TS} 2_{\text {new }}-\mathrm{TS} 1_{\text {melt }}}{\mathrm{R} 12}+\mathrm{QOL}+\mathrm{QSL}-\mathrm{MC} 1\left(\mathrm{TS} 1_{\text {melt }}-\mathrm{TS} 1_{\mathrm{old}}\right)$

and, correspondingly, the mass of stainless steel that melts during the time step.

\section{Debris Interaction With Core Plate}

There are four potential sources for molten or partially molten material which may move below the bottom of the active core. These four sources are:

- melting of core structures,

- in-core molten pool

- upper plenum structure melting,

- user-defined slumping

As formerly modeled, molten material that drained downward from the core was either ignored, or, if a COUPLE mesh had been defined, fell directly into the lower plenum with no history of the source of the material. This interface logic was modified to redirect the flow of molten material from any source such that it first passes through the core plate model. If no core plate has been specified, the debris sources are combined to form the scalar variables representing each of the tracked species which is then used by the FCI or COUPLE model as appropriate. If a core plate is modeled, then the material impinges upon the appropriate plate, and is handled by the core plate model until the material falls through to the FCI model, as shown in Figure 12.

If sufficient detail is specified by the user, a portion of the core plate model may be modeled as being directly below and connected to, each annular ring in the core region. Within an annular ring the debris material will be represented with a uniform height (i.e., self-leveling) across the horizontal surface. Mass transfer to an adjacent annular ring will occur, either when the volume associated with the core plate is filled with debris, or alternatively when the debris height reaches a user-defined value. 


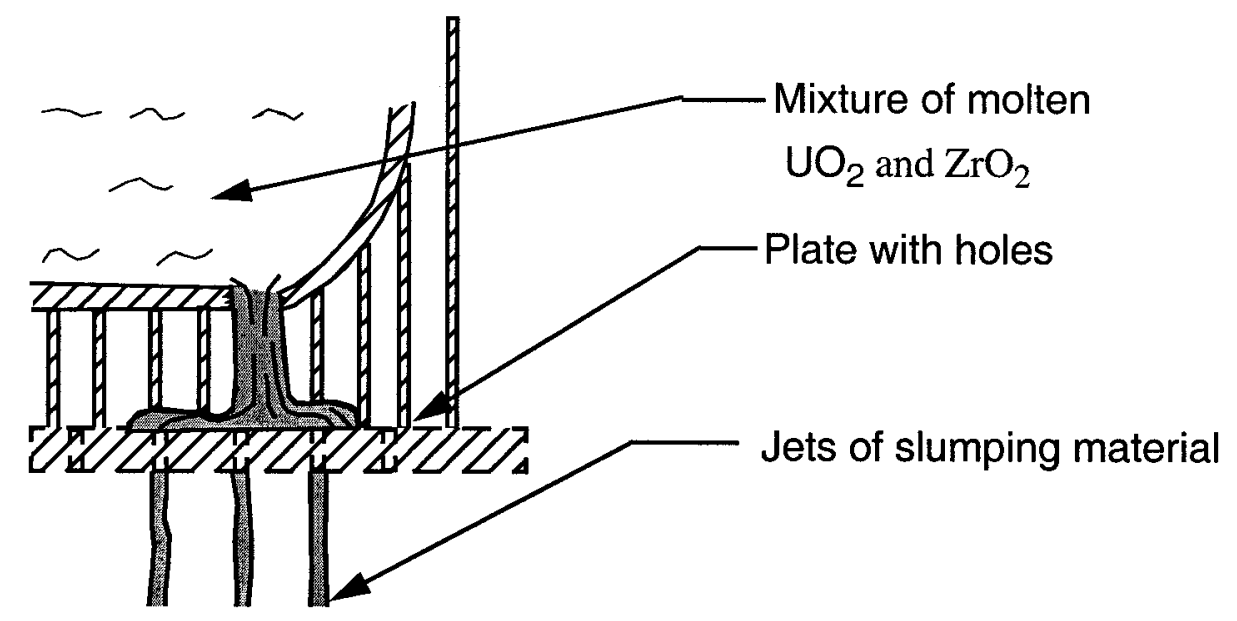

Figure 12. Representation of molten pool failure and material relocating to core plate.

\section{Heat Transfer}

As material is relocated to the upper surface of the core plate, the core plate model has the capability of tracking the formation of a pool of molten material above the plate, and the transfer of heat across a crust of solidified material which may form between molten debris material and the core plate.

For steady state heat transfer, data are usually correlated in terms of the surface-averaged Nusselt number, $\mathrm{Nu}$, a modified Rayleigh number, $\mathrm{Ra}$, and the fluid Prandtl number, Pr, which are defined by

$\mathrm{Nu}=\frac{\mathrm{hL}}{\mathrm{k}}=\frac{\mathrm{q}^{\prime \prime}}{\frac{\mathrm{k}}{\mathrm{L}} \Delta \mathrm{T}}$

$\mathrm{Ra}=\frac{\mathrm{G} \beta \mathrm{q}^{\prime \prime \prime} \mathrm{L}^{5}}{\alpha v \mathrm{k}}$

$\operatorname{Pr}=\frac{v}{\alpha}$

where

$\mathrm{k}=\quad$ thermal conductivity of the liquid in the molten pool $(\mathrm{W} / \mathrm{m} \mathrm{K})$

$\mathrm{h} \quad=\quad$ average heat transfer coefficient $\left(\mathrm{W} / \mathrm{m}^{2}-\mathrm{K}\right)$

$\mathrm{L}=$ a characteristic length; in a rectangular geometry, this study has used the pool height $(\mathrm{m})$

g $=$ acceleration due to gravity $\left(\mathrm{m} / \mathrm{s}^{2}\right)$

$\beta=\quad$ volumetric coefficient of expansion $(1 / \mathrm{K})$

$\alpha \quad=\quad$ thermal diffusivity $\left(\mathrm{m}^{2} / \mathrm{s}\right)$ 


$\begin{array}{lll}v & = & \text { kinematic viscosity }\left(\mathrm{m}^{2} / \mathrm{s}\right) \\ \mathrm{q}^{\prime \prime \prime} & = & \text { volumetric heat generation rate }\left(\mathrm{W} / \mathrm{m}^{3}\right) . \\ \mathrm{q}^{\prime \prime} & = & \text { heat flux from molten pool }\end{array}$

For transient heat transfer, data may be correlated using the Fourier number, Fo, and the transient Rayleigh number, Ra', which are defined by

$\mathrm{Fo}_{\mathrm{O}}=\frac{\alpha \mathrm{t}}{\mathrm{L}^{2}}$

$\mathrm{Ra}^{\prime}=\frac{\mathrm{Ra}}{\mathrm{Nu}}$

As part of the part of the design report for molten pool improvements ${ }^{13}$, Dr. J.L. Rempe assessed the applicability of empirical correlations for molten pool heat transfer ${ }^{14}$. This was done by comparing the range of conditions over which the data from which the correlations were obtained, to the range of conditions expected during a severe LWR accident. As a part of this task, representative ranges for the dimensionless groups were quantified using representative upper and lower input values and using results from a representative SCDAP/RELAP5 calculation ${ }^{8}$. Values estimated from these sources are summarized in Table 6. Using the values from this table, Dr. Rempe estimated that lower head pools would range from a Rayleigh number of $10^{13}$ to $10^{17}$, and that debris Prandtl number would range from 0.03 to 0.8 .

Table 6. Range for variables used to estimate pool heat transfer parameters,

\begin{tabular}{|c|c|c|c|}
\hline Property & $\begin{array}{c}\text { Ceramic (UO2 at } \\
\sim 3200 \mathrm{~K})\end{array}$ & $\begin{array}{c}\text { Metallic Material (SS- } \\
304 \text { at } \sim 1700 \mathrm{~K}\end{array}$ & $\begin{array}{c}\text { 80\% UO2/20\% ZrO2 } \\
\text { (by weight) at 2900 } \\
\mathrm{K}\end{array}$ \\
\hline \hline$\rho, k g / m 3$ & 8400 & 7250 & 9300 \\
\hline$c p, \mathrm{~J} / \mathrm{kg}-\mathrm{K}$ & 500 & 560 & 650 \\
\hline$k, \mathrm{~W} / \mathrm{m}-\mathrm{K}$ & 3.8 & 38 & 3.8 \\
\hline$\beta, K^{-1}$ & $1.6 e-4$ & $3.5 e-4$ & $7.51 e-5$ \\
\hline$\alpha, \mathrm{m}^{2} / \mathrm{s}$ & $9.0 e-7$ & $9.4 e-6$ & $6.2 e-7$ \\
\hline$v, \mathrm{~m}^{2} / \mathrm{s}$ & $5.4 e-7$ & $3.2 e-7$ & $4.8 e-7$ \\
\hline$P r$ & 0.6 & 0.03 & 0.8 \\
\hline
\end{tabular}

Dr. Rempe recommended that the correlations proposed by Steinberner and Reineke ${ }^{15}$ are the most applicable for pools that may form during a severe accident. These correlations were obtained from facilities at higher Rayleigh numbers (between $8 \times 10^{12}$ and $4 \times 10^{13}$ ), and they appear to be consistent with much of the data obtained from lower Rayleigh number investigations. Based upon this recommendation, 
the lower core plate model uses the Steinberner and Reineke correlation for rectangular geometries.

$$
\begin{aligned}
& \mathrm{Nu}_{\mathrm{u}}=0.345 \mathrm{Ra}^{0.233} \\
& \mathrm{Nu}_{\mathrm{d}}=1.389 \mathrm{Ra}^{0.095}
\end{aligned}
$$

\section{Debris Interaction During Core Plate Penetration}

The heart of the core plate model will be the modeling of material flow through the plate and the potential blockage of the penetrations through the core plate. Without a blockage, relocating material will flow through the core plate region with no delay, and the model will have minimal impact upon the analysis. Two approaches have been used to model core plate blockage, depending on whether or not the debris is primarily metallic or ceramic.

\section{Metallic Blockage}

The justification for modeling metallic blockage of the core plate is that the XR2-1 experiment (refer to XR2-1 Experiment Results on page 15) indicates that, at least for BWR geometries, molten metallic material will relocate downward into the core plate region, solidify to form localized (non-coherent blockages, and then remelt in response to continued heating of the structures. Modeling the flow of molten metallic material through the core plate penetrations is done by modeling a vertical structure of the same material as the plate, with molten debris flowing past it. Calculation of mass and heat transfer is performed in a manner identical to that used for flow of the metallic material over the core component surface. As material freezes on the wall, the flow area through the penetration is reduced, as shown in Section 13, and if appropriate, plugged.

\section{Ceramic Blockage}

The available information about damage progression in the core plate region during the late phase of a severe accident (when the ceramic material forms an in-core porous debris bed and molten pool) is less definitive than that for metallic debris. The XR2-1 experiment did not address the late phase, but recent BWR and PWR accident simulations (See "PHENOMENOLOGY" on page 9.) predict that a large molten ceramic pool will propagate, either downward past the bottom of active fuel or peripherally to the core barrel and then downward into the core plate region. The core plate model must then determine whether this molten ceramic material quickly flows through the core plate penetrations, or whether the penetrations are plugged, thereby forcing the molten ceramic to melt through the core plate.

The results of experiments on $\mathrm{UO}_{2}$ fuel flow and freezing are not consistent with the typical concept of molten material freezing on the sides of the penetration until sufficient crust growth plugs the penetration, as described in the previous section. A conduction controlled analytical formulation for solidification predicts that molten material penetrates significantly greater distances before plugging occurs than is experimentally observed ${ }^{17}$. It has been concluded that $\mathrm{UO}_{2}$ flowing over steel behaves in a manner that prevents the formation of a stable crust at the wall and, therefore, $\mathrm{UO}_{2}$ penetration is 


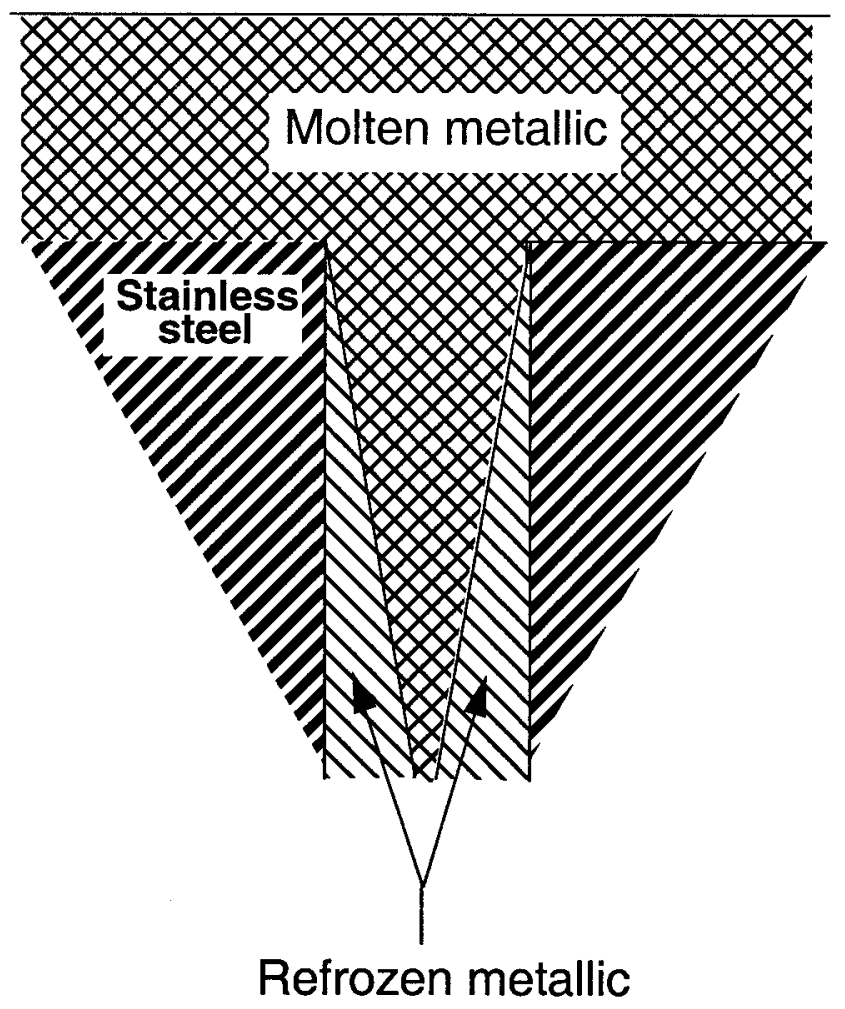

Figure 13. Blockage of core plate penetrations by metallic material.

controlled by turbulent heat transport from the slug of molten ceramic material to the structure. This conclusion leads to the concept of the material flow illustrated in Figure 14, which shows the existence of a two-phase ceramic slurry flowing through the core plate penetration with no crust formation along the walls. In such a case, the plugging of the core plate penetrations can not be modeled using the traditional methods described for the metallic plugging.

In order to model the plugging of the core plate penetrations by molten ceramic material, a correlation for the penetration of a flowing ceramic through a steel channel ${ }^{16}$ is used. If the correlation predicts that the slurry will penetrate a distance less than the core plate thickness, then the penetration will be modeled as plugged. This correlation for the core plate penetration distance is:

$X_{P}=\frac{1}{2} \frac{D}{f}\left(\frac{\frac{L_{f}}{c_{f}}+T_{f, 0}-T_{f, m p}}{T_{f, 0}-T_{s, m p}}\right)\left(\frac{1}{1+\frac{T_{f, m p}-T_{s, m p}}{\frac{L_{s}}{c_{s}}+T_{s, m p}-T_{s, 0}}}\right)$

where

$$
\mathrm{X}_{\mathrm{p}} \quad=\text { Penetration distance }
$$




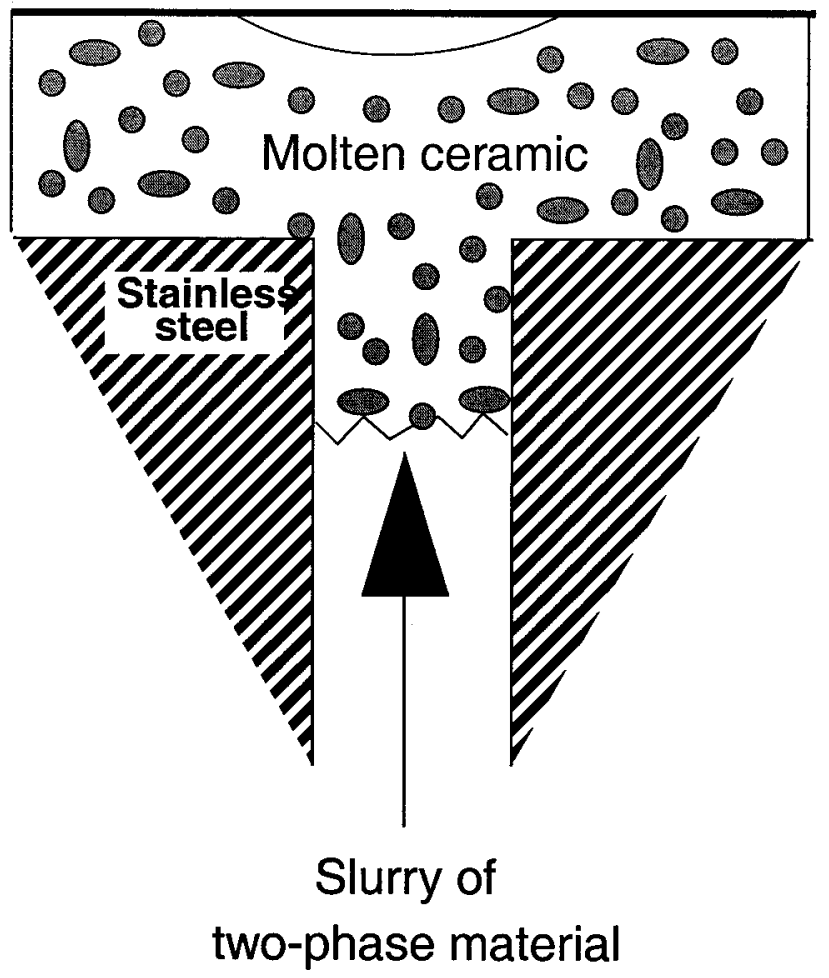

Figure 14. Blockage of core plate penetration by ceramic material.

$\mathrm{D}$

$=$ channel diameter

$\mathrm{f} \quad=$ coefficient of friction

$\mathrm{L} \quad=$ latent heat of fusion

c = heat capacity

$\mathrm{T}=$ Temperature (subscripts $\mathrm{f}=$ fuel, $\mathrm{s}=$ steel, $\mathrm{mp}=$ melting point, $0=$ temperature at channel entrance or initial wall temperature.

The method in which the core plate model interacts with either the Fuel-Coolant Interaction (FCI) model or the COUPLE module is very straightforward. In the event that no core plate structure has been defined, then slumping mass and energy from each of the four potential sources is summed and then delivered to the FCI model in the manner experienced before the core plate model was implemented. It should be noted that the material is modeled as arriving at the lower head in a single large jet. If a core plate structure is defined, then the material leaving the lowest plate is delivered to the FCI model, and is represented as arriving as the same number of jets as surviving penetrations. 


\section{VALIDATION OF THE CORE PLATE MODEL \\ Simple Cheap Vessel Problem}

The Simple Cheap Vessel Problem (SCVP) is a benchmark problem sent with each code transmittal, which is fast running but tests the heatup of core components and the relocation of core material into the lower head. The hydrodynamic model consists of two parallel flow channels with time-dependent volumes at each end to set flow conditions, as shown in Figure 15. Each flow channel has a fuel rod component, representing 18,408 fuel rods, and a control rod component representing $118 \mathrm{Ag} / \mathrm{In} / \mathrm{Cd}$ control rods. These core components are connected to a COUPLE mesh representing the lower vessel head.

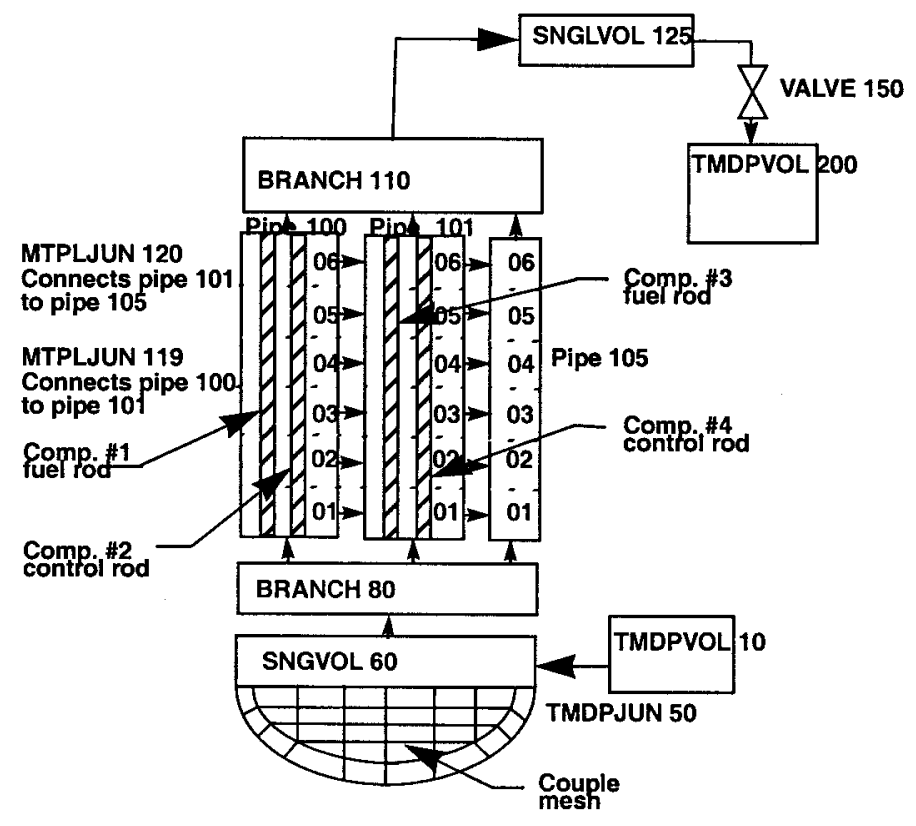

Figure 15. Nodalization of Simple Cheap Vessel Problem

The simulation is conducted under conditions which are intended, not to provide prototypical response, but instead to drive the simulation into core melting and relocation in an accelerated manner. The simulation is therefore initiated with the fuel rods at the following conditions:

- a uniform temperature of $900 \mathrm{~K}$,

- a constant core power of $934 \mathrm{MW}$, and

- a saturated steam environment.

Because the objective of the problem is to generate debris slumping as rapidly as possible, it was understood that the probability of debris freezing on the core plate was low, and the primary purpose of the simulation was to test the interface logic between the core relocation module, the lower core plate module, and the lower head module. Using debug output, the linkages and mass/energy balances across the lower core plate model was debugged and eventually verified. Since the only effect of the presence of a core plate in the problem was to delay the arrival of slumping corium by a few seconds, no additional testing could be done using this problem. 


\section{User-Defined Slumping Problem}

As described in the preliminary design report, the core plate model has the capability of taking a description of molten material slumping onto the plate, not from the SCDAP/RELAP5 core or upper plenum models, but from user input. The advantage of this capability is that a code user may define slumping characteristics directly, rather than specifying parameters (such as power or thermal/hydraulic conditions) which may affect the slumping characteristics only indirectly. The user-defined slumping problem simulates a core plate of three annular sections of equal surface area with a source of slumping material just above the outermost annular ring, as shown in Figure 16. This geometry was chosen as the most probable scenario to occur during an application by a code user, because it simulates the breach of an in-core molten pool with molten material flowing down the periphery of the core.

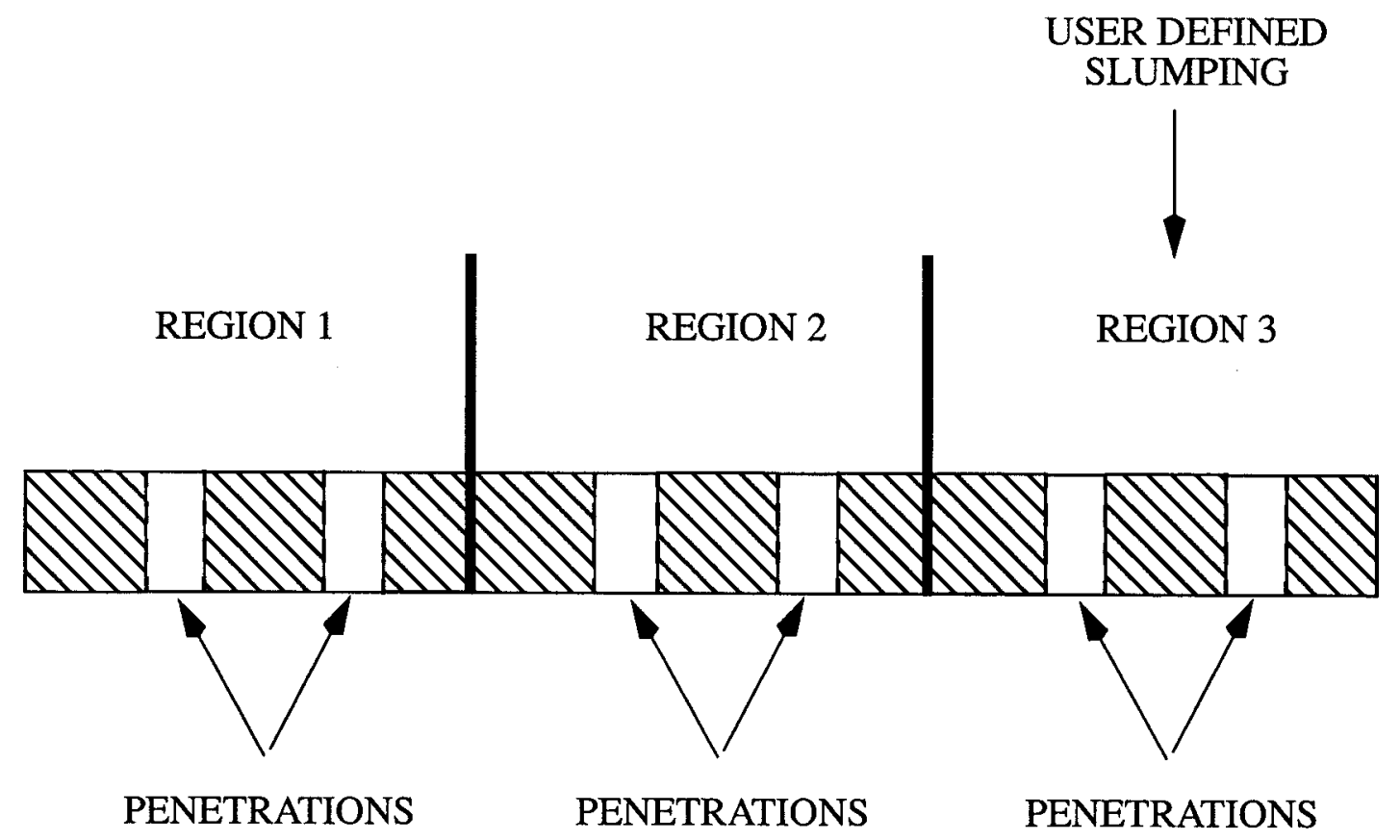

Figure 16. User defined slumping problem geometry.

The most effective manner of applying this problem was to define two periods of slumping, as shown inTable 7. The first slump consists of metallic material at it's melting temperature, and the second slump consists of molten UO2. The first slump is intended to freeze on the core plate, blocking the core plate penetrations, and the second is then required to melt through the plate. The first slump relocated to the core plate, spread across the plate, and after permitting approximately $28 \mathrm{~kg}$ of metal to pass through the platess, did freeze and plug the core plate penetrations. The second slump then came down on top of the first material, and after approximately 80 seconds, did melt through the core plate. In retrospect, this problem did point out a potential for refinement in the model, because the calculation of core plate melting is performed assuming solid stainless steel. A better approach might have been to perform two melting calculations, the first across the core plate material, and the second across the plugged penetrations. In this 
manner, it may have been possible to re-open the plugged penetrations before melting the core plate..

Table 7. Summary of user-defined slumpings

\begin{tabular}{|c|c|c|c|}
\hline Slump \# & $\begin{array}{c}\text { Primary } \\
\text { Consitutent }\end{array}$ & Temp (K) & Mass (kg) \\
\hline \hline 1 & $A g$ & 1100 & $100 \mathrm{~kg}$ \\
\hline 2 & $U O 2$ & 3300 & $2000 \mathrm{~kg}$ \\
\hline
\end{tabular}




\section{CONCLUSIONS}

This report describes the implementation and testing of a model which will significantly extend the capabilities of the SCDAP/RELAP5 code to model the core plate region of either a PWR or BWR plant. Such a model is necessary because experimental evidence, as well as several analyses, have indicated that metric tons of molten core material can relocate into and through the core plate region. If oxidation in the core is limited by the availability of steam, and if the lower head still contains coolant, then the relative timing of the arrival of molten core material into that coolant can be significant to the course of the accident analysis. This model treats the thermal response of the structures in the core plate region as molten material relocates downward from the core, through the core plate region, and into the lower plenum.

A survey has been performed to characterize the structures in the core plate regions of both PWR and BWR designs. Additionally, a survey of available experimental data and several recent analyses for both PWR and BWR plants was performed to characterize the range of conditions which a core plate model could be expected to experience. The survey of geometries showed that a wide variety of core plate geometries must be modeled, with thicknesses varying from 5 to $55 \mathrm{~cm}$. The data survey demonstrated that relocation, whether from a PWR or BWR core, may occur in two stages. The first stage consists of metallic debris with a total mass on the order of 1-14 metric tons, and approximately at it's melting point. The second consists of a composite, primarily ceramic in nature, of $\mathrm{UO}_{2}, \mathrm{ZrO}_{2}$, and metals, and may have a total mass in the range from of 80 to 130 metric tons. The material will be non-homogeneous, and may only be $70 \%$ molten, with entrained solids. The average molten material temperatures will be close to the melting temperature of $\mathrm{UO}_{2}$, although highly localized regions may be as high as 3900-4000 K. 


\section{REFERENCES}

1 SCDAP/RELAP5/MOD 3.2 Code Manual, NUREG/CR-6150 Rev. 1, Idaho National Engineering and Environmental Laboratory, October 1997.

2 C.M. Allison and S.A. Chavez, Proposed SCDAP/RELAP5/MOD3.1 Model Additions to Treat the Behavior of Upper Plenum and Core Plate Structures During the Later Phases of a Severe Accident (Draft), EGG-RAAM-11500, September 1994.

3 Final Safety Analysis Report, Three Mile Island Unit 2, Metropolitan Edison Company.

$4 \quad$ Final Safety Analysis Report, Waterford Steam Electric Station Unit 3, Energy Operations Incorporated.

$5 \quad$ Final Safety Analysis Report, Calvert Cliffs Units 1 and 2, Baltimore Gas and Electric Company.

6 Final Safety Analysis Report, Braidwood Nuclear Power Plant Unit 1, Commonwealth Edison Company.

$7 \quad$ Final Safety Analysis Report, Zion Station, Commonwealth Edison Company.

8 M.M. Pilch, et al., The Probability of Containment Failure by Direct Containment Heating in Surry, Appendix E, NUREG/CR-6109, May 1995.

9 M.M. Pilch, et al., The Probability of Containment Failure by Direct Containment Heating in Zion, Appendix C, NUREG/CR-6075 Supp. 1, December 1994.

10 F. P. Griffin, SCDAP/RELAP5 Mod 3.2 Simulations For the Browns Ferry BWR Design, ORNL/ NRC/LTR-97/27, letter report to Dr. Y. Chen, Accident Evaluation Branch, Division of Systems Technology, RES, NRC, December 16, 1997.

11 R. O. Gauntt and L. L. Humphries, Final Results of the XR2-1 BWR Metallic Melt Relocation Experiment, NUREG/CR-6527, SAND97-1039, Sandia National Laboratories, August 1997.

12 M. Jahn and H. H. Reineke, "Free Convection Heat Transfer with Internal Heat Source, Calculations and Measurements," Proceedings of the International Meeting on Thermal Nuclear Reactor Safety, NUREG/CR-0027, 2, February 1983, pp. 996-1010.

13 C. M. Allison, J. L. Rempe, and S. A. Chavez, Final Design Report on SCDAP/RELAP5 Model Improvements - Debris Bed and Molten Pool Behavior, INEL-96/0487, December 1996.

14 J.L. Rempe and C.M. Allison, "Improved Models for Predicting Heat Transfer from a Molten Pool", Thermal Hydraulic Division Proceedings of the 1995 ANS Winter Meeting, October 1995.

15 U. Steinberner and H.H. Reineke, "Turbulent Buoyancy Convection Heat Transfer with Internal Heat Sources”, Proc. 6th Int. Heat Transfer COnf., Vol. 2, pp305-310, Paper NC-21, toronto, Canada, August 1978.

16 M. Epstein, et al., "Transient Freezing of a Flowing Ceramic Fuel in a Steel Channel”, Nuclear Science and Engineering: 61, 310-323 (1976).

17 D.H. Cho, M. Epstein, R.P. Anderson, D.R. Armstron, “Transient Freezing in a Tube Flow," in Reactor Development Program Progress Report, ANL-RDP-37, 7.12, Argonne National Laboratory (1975). 
